\title{
ESPAÇOS LIVRES PRIVADOS NAS PEQUENAS CIDADES
}

\author{
PRIVATE OPEN SPACES IN SMALL TOWNS
}

\author{
Cláudia Maté* \\ Alina Gonçalves Santiago**
}

\section{RESUMO}

As cidades pequenas são maioria no cenário nacional, no entanto ainda são poucas as pesquisas desenvolvidas acerca da realidade dessas cidades, principalmente a respeito de seu espaço urbano. Da mesma forma, os estudos desenvolvidos a respeito do sistema de espaços livres também têm se concentrado em grandes e médias cidades brasileiras. Nesse contexto, este artigo tem como objetivo analisar os Espaços Livres Privados (ELPr) de uma pequena cidade, Pinhalzinho, no estado de Santa Catarina, identificando suas particularidades e também as similaridades e diferenças existentes com os resultados já encontrados nos estudos de cidades de maior porte. A metodologia adotada tem como referência principal os estudos dos sistemas de espaços livres desenvolvidos pela Rede Nacional de Pesquisa Quapá-SEL, com o uso da interface Sistemas de Informação Geográfica para identificação, categorização, quantificação e análise dos espaços livres privados. A análise destes resultou em altas taxas de espaço livre intraquadra e na predominância de espaços verdes e permeáveis, aspectos bem particulares à pequena cidade em estudo.

Palavras-chave: Cidade pequena. Espaços Livres Privados. Pinhalzinho.

\section{ABSTRACT}

In the Brazilian urban scenario, small towns are the most common type of settlement; however, they are rarely addressed by urban studies, especially regarding their urban space. Likewise, the studies concerning the open space system are also concentrated in medium and large Brazilian cities. In this context, this paper aims to investigate the private open spaces of a small town, Pinhalzinho/SC, identifying its specificities and also observing the similarities and differences between the results already found in larger urban centers. The adopted method has the studies of open space systems developed by the National Research Network Quapá-SEL as main reference, using the GIS interface for identification, categorization, quantification, and analysis of private open spaces. As a result, the analysis of private spaces shows high rates of open space within blocks and the predominance of vegetated and pervious surfaces-specific aspects of the small town investigated.

Keywords: Small Town. Private Open Spaces. Pinhalzinho.

\footnotetext{
* Universidade Federal de Santa Catarina, Programa de Pós-Graduação em Arquitetura e Urbanismo (PósARQ/CTC-UFSC). Campus Reitor João David Ferreira Lima, s/n, CEP 88040-900, Trindade, Florianópolis, SC, Brasil. CV: http://lattes.cnpq.br/6071186026217896 claudiaamate@gmail.com

** Universidade Federal de Santa Catarina, Programa de Pós-Graduação em Arquitetura e Urbanismo (PósARQ/CTC-UFSC). Campus Reitor João David Ferreira Lima, s/n, CEP 88040-900, Trindade, Florianópolis, SC, Brasil.

CV: http://lattes.cnpq.br/5182318318276740

alinagsantiago@hotmail.com
} 


\section{INTRODUÇÃO}

Este artigo é resultado da dissertação intitulada 'A cidade pequena através de seu sistema de espaços livres - o caso de Pinhalzinho/SC' (MATÉ, 2016), desenvolvida no Programa de Pós-Graduação de Arquitetura e Urbanismo da Universidade Federal de Santa Catarina (PósARQ/UFSC). A pesquisa surgiu da demanda por estudos e métodos de análise aplicáveis às pequenas cidades e suas peculiaridades, buscando melhor caracterizar seus territórios e suas dinâmicas.

Mesmo representando a maioria no cenário nacional - cerca de $70 \%$ dos municípios brasileiros possuem população inferior a 20 mil habitantes -, o estudo desses pequenos núcleos não tem sido um dos temas prioritários na produção de conhecimento sobre a cidade (SPOSITO; DA SILVA, 2013). De modo geral, os estudos urbanos têm se dedicado à compreensão das médias e grandes cidades, sobretudo das metrópoles. Assim, persistem as dificuldades relacionadas à análise das pequenas, tanto pela carência de parâmetros de definição e metodológicos como pela diversidade da realidade socioespacial brasileira (SOARES, 2009).

Da mesma forma, os estudos desenvolvidos a respeito do sistema de espaços livres urbanos, públicos e privados, também têm se concentrado em metrópoles e grandes cidades. A discussão nacional sobre os espaços livres tem possibilitado o estabelecimento de padrões comuns de configuração, gestão, distribuição e apropriação desses espaços, e, assim, maior compreensão sobre a realidade urbana nas cidades brasileiras de maior porte.

A importância das análises sobre os espaços livres das pequenas cidades se fundamenta no fato de que estas comumente apresentam proximidade com o ambiente rural e o natural, realidade distante nos grandes núcleos. Ao mesmo tempo, nessas cidades também é frequente a adoção de modelos de planejamento, planos diretores ou padrões formais de cidades maiores. Macedo (1995) explica que a reprodução desses modelos raramente considera as condições locais e o impacto ambiental, sendo propostas soluções inadequadas em relação à morfologia do relevo e ao clima, desvinculadas do cotidiano e costumes locais.

Nesse sentido, a análise do sistema de espaços livres em uma cidade pequena pode identificar suas particularidades, investigando como a influência das cidades maiores e a inter-relação entre o rural e o urbano se refletem em seu espaço urbano, na forma, nas tipologias, nos padrões de uso e distribuição dos espaços livres urbanos. Ao analisar a importância que os espaços livres tiveram na organização das cidades de pequeno porte e as consequências que sofreram frente à ocupação urbana e à maneira como ela se desenvolveu, é possível compreender a realidade urbana desses núcleos.

Este artigo concentra-se no estudo dos Espaços Livres Privados (ELPr) de uma cidade de pequeno porte - Pinhalzinho - com o objetivo de investigar suas tipologias, seus usos e distribuição, e sua relação com o perfil socioeconômico da população. 


\section{OS ESPAÇOS LIVRES PRIVADOS}

Os espaços livres urbanos são definidos por Magnoli (1982) e Macedo (1995) como todos os espaços 'livres de edificação', ou seja, todos os espaços descobertos, sejam vegetados ou pavimentados, públicos ou privados, produzidos de modo formal ou informal. Desse modo, espaço livre é todo espaço não ocupado ou coberto por volume edificado e que está diretamente associado ao entorno das edificações e às atividades humanas (CUSTÓDIO et al., 2013).

Os ELPr são aqueles inseridos em áreas particulares ou terrenos privados desocupados, cujo acesso não é em geral possibilitado ao público. É nesses espaços que ocorre grande parte da vida cotidiana da habitação, do trabalho, convívio familiar e social e recreação (QUEIROGA, 2011). Esses espaços constituem boa parte dos espaços livres das cidades brasileiras, apresentando importância no sistema de espaços livres urbanos sobretudo pelo aspecto de complementaridade funcional, mas também contribuindo em aspectos ambientais (QUEIROGA, 2014).

A distribuição e a conformação dos ELPr influenciam diretamente na paisagem urbana das cidades brasileiras. Segundo Queiroga et al. (2011), há uma relação de dependência entre os espaços livres e a massa construída e, na maioria dos casos, os ELPr são caracterizados por intensa fragmentação e encontram-se dispersos no tecido urbano.

Além de apresentarem grande vulnerabilidade no espaço urbano, por serem constantemente interpretados como espaços ainda livres e no aguardo de algum tipo de ocupação, tais espaços também acabam sendo os mais suscetíveis a transformações (TÂNGARI; ALMENTEIRO; PARAHYBA, 2012). Os autores apontam que, ainda que regulamentados pela legislação, são frequentemente ocupados informalmente, de forma não coletiva, definida por anseios particulares, afetando a relação 'cheios e vazios', a qualidade e quantidade de insolação e a ventilação.

Tais espaços livres dificilmente resistem às transformações advindas das necessidades da população e são transformados e minimizados, até mesmo extintos, para atender demandas específicas, como a construção de um novo cômodo ou cobertura para um automóvel (QUEIROGA et al., 2011). O reduzido tamanho dos ELPr é um dos padrões observados nas grandes e médias cidades analisadas pela Rede Quapá-SEL. Conforme Queiroga et al. (2011), a maioria das áreas urbanas consolidadas apresenta espaços livres inferiores a 50\% da área das quadras, sendo a condição mais frequente destas com menos de 30\% de espaços livres.

A Rede Quapá-SEL tem como um de seus instrumentos de trabalho a confecção de mapas temáticos que buscam caracterizar a morfologia urbana das cidades e facilitar a compreensão do espaço e da forma urbana e sua relação com os espaços livres. Entre os mapeamentos desenvolvidos, destacam-se dois neste artigo: 1) espaço livre de edificação intraquadra; 2) verticalização por quadra.

O primeiro objetiva avaliar o quanto se tem de espaços livres dentro das quadras urbanas independentemente de seus usos, sejam eles jardins, corredores, pátios de 
descarga ou estacionamentos (CAMPOS, 2010). Para esse mapeamento foram estabelecidas três categorias: quadras com até $30 \%$ de espaço livre; quadras com $30 \%$ a $50 \%$ de espaço livre e quadras com mais de $50 \%$ de espaço livre (CAMPOS et al., 2009).
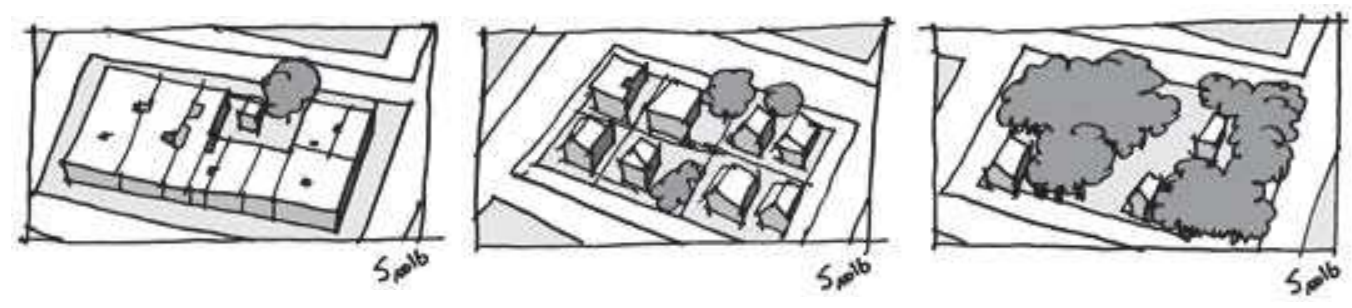

Figura 1 Categorias de EL Intraquadra: quadras com até 30\%, de 30\% a 50\% e com mais de $50 \%$ de espaço livre, respectivamente.

Fonte: Caderno Quapá-SEL São Paulo - Acervo Quapá-SEL, 2016.

O segundo mapa temático - de verticalização por quadra - busca avaliar a intensidade e a localização da verticalização no espaço urbano das cidades brasileiras. Para esse mapeamento foram estabelecidas três faixas: até $10 \%$ de verticalização na quadra, de $10 \%$ a $50 \%$ de verticalização na quadra e mais de $50 \%$ de verticalização na quadra (CAMPOS et al., 2009), sendo que as edificações consideradas verticalizadas são aquelas com mais de três ou quatro pavimentos, variando de acordo com o estudo.

As análises procedentes desses mapeamentos têm evidenciado o adensamento construído das áreas urbanas consolidadas tanto nas metrópoles como nas cidades grandes e médias avaliadas (MACEDO et al., 2009). Observa-se uma predominância, nas áreas centrais, de tecidos urbanos com no máximo 30\% de espaços livres e até $50 \%$ de verticalização intraquadra, características que conferem altos índices de impermeabilização, escassez de vegetação e problemas de insolação e ventilação.

Outra característica verificada é a predominância de quadras horizontais no tecido urbano das cidades analisadas e a concentração de quadras densamente verticalizadas nas áreas centrais e ao longo dos grandes eixos viários (CAMPOS, 2010; CAMPOS et al., 2009). É importante destacar que, devido ao método adotado, quadras com até $10 \%$ de área verticalizada podem apresentar tanto uma verticalização pontual como quadras totalmente horizontais.

Em síntese, os mapas de espaços livres de edificação intraquadra e verticalização intraquadra apontam a alta densidade construída e a baixa incidência de espaços livres intralote como características recorrentes nas grandes e médias cidades brasileiras (CAMPOS, 2010). Diante desses resultados, e da evidente lacuna quanto ao estudo do sistema de espaços livres urbanos nas pequenas cidades, sentiu-se a necessidade de verificar se as características dos espaços livres nas grandes e médias cidades brasileiras são recorrentes nas pequenas, visto que, normalmente, o desenvolvimento de seus planos diretores é norteado pelos das cidades maiores. 


\section{A CIDADE DE ESTUDO}

A escolha de Pinhalzinho como estudo de caso se deu, primeiramente, por enquadrar-se na categoria de cidade de pequeno porte diante de seu contingente populacional de 18.284 mil habitantes (IBGE, 2014) e por estar localizado no oeste de Santa Catarina, região tipicamente rural e fortemente marcada pela agropecuária e agroindústria (SOUZA, 2009). A escolha do município também partiu da sua importância como centro local regional da mesorregião Oeste (IBGE, 2008) e por ter apresentado contínuo crescimento populacional nos últimos anos, em meio a uma região caracterizada pelo decrescimento populacional (IBGE, 2014).

É importante destacar que o Oeste Catarinense se caracteriza pela predominância das pequenas cidades em seu território e pela importância do espaço rural na dinâmica e na distribuição demográfica da região. Como aponta Mattei (2011), a grande maioria dos municípios do Oeste, mesmo os considerados urbanos, ainda mantém sua base rural e a integração entre produtores familiares e as agroindústrias, contexto que reflete na economia dos municípios e nas relações cotidianas de sua população urbana e rural.

O espaço urbano de Pinhalzinho é formado pelos perímetros urbano e industrial, ambos estabelecidos pelo Plano Diretor Municipal (PINHALZINHO, 2012). Os acessos a Pinhalzinho se dão pelas rodovias BR-282 e SC-469 - a primeira tendo grande importância não somente para a mesorregião Oeste, mas para todo o estado, promovendo integrações socioeconômica, política e cultural entre as diferentes regiões catarinenses. Devido à expansão urbana crescente em direção às rodovias, o fluxo de veículos, principalmente os de carga, está cada vez mais interligado ao tráfego na malha urbana.

Na figura 2 são ilustrados os perímetros urbano e industrial, as rodovias que cortam o território municipal e a mancha urbana de Pinhalzinho em 2010. A malha urbana do município ocupa cerca de $3.450 .000 \mathrm{~m}^{2}\left(3,45 \mathrm{~km}^{2}\right)$, e a somatória dos perímetros industrial e urbano, incluindo áreas destinadas à expansão urbana, é de $10 \mathrm{~km}^{2}$ correspondendo a $12,83 \%$ do território municipal. No perímetro urbano, os habitantes distribuem-se em dez bairros. De acordo com dados municipais, a população urbana concentra-se principalmente nos bairros centrais: Centro, Pioneiro e Nova Divineia.

Na sequência pode-se observar os mapeamentos de uso e ocupação do solo e de gabarito das edificações do perímetro urbano. Na figura 3 verifica-se a concentração de diferentes usos no bairro Centro e ao longo dos principais eixos viários que cruzam a área central. Essa concentração de diversos usos contrasta com o predomínio do uso residencial nos bairros adjacentes ao Centro, especialmente em relação às áreas mais periféricas. A predominância residencial é observada em toda a cidade: do total de 5.313 edificações levantadas, 4.279 são residenciais - mais de $80 \%$ do total.

Já na figura 4 pode-se observar que a verticalização também se concentra no Centro e, em menor intensidade, nas vias principais. A grande maioria das edificações, cerca de $97 \%$, possui até dois pavimentos. Ao relacioná-las com a figura 3, estas edificações 
abrigam indústrias, as instituições e a maior parte das residências, comércio e serviço. As edificações com mais de três pavimentos, apenas 3\% total municipal, abrigam uso misto e residencial. Das 158 edificações consideradas verticalizadas, somente nove possuem mais de oito pavimentos e, mesmo possuindo edifícios de até 16 pavimentos, o pequeno número de edificações com mais de três pavimentos mostra como a verticalização é pontual no município.

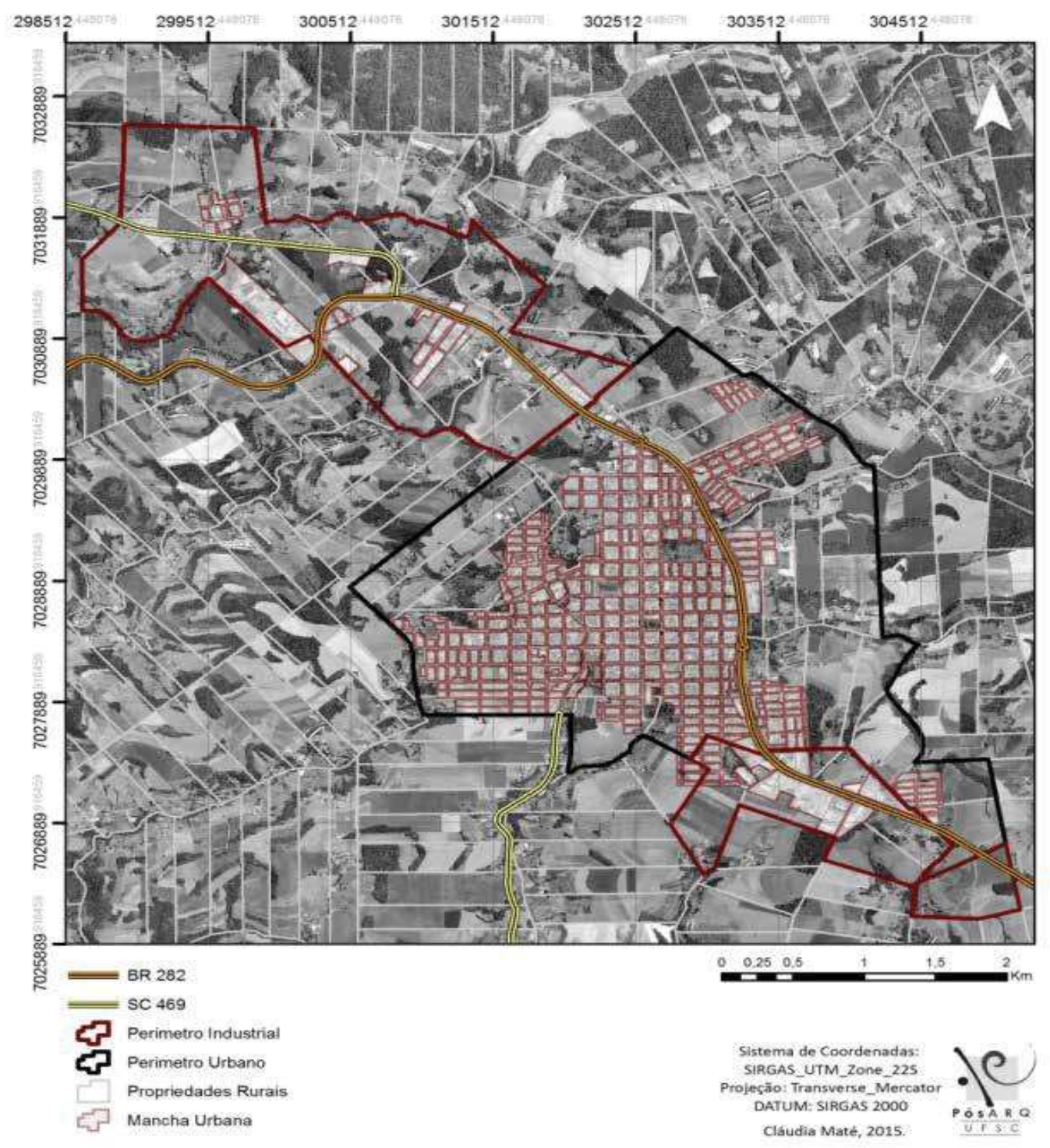

Figura 1 Mapa dos perímetros urbano e industrial de Pinhalzinho com destaque para as rodovias BR-282 e SC-469.

Fonte: Elaborado por Cláudia Maté, 2015, com base no mapa cadastral e dados vetoriais da Prefeitura Municipal de Pinhalzinho (2010). 

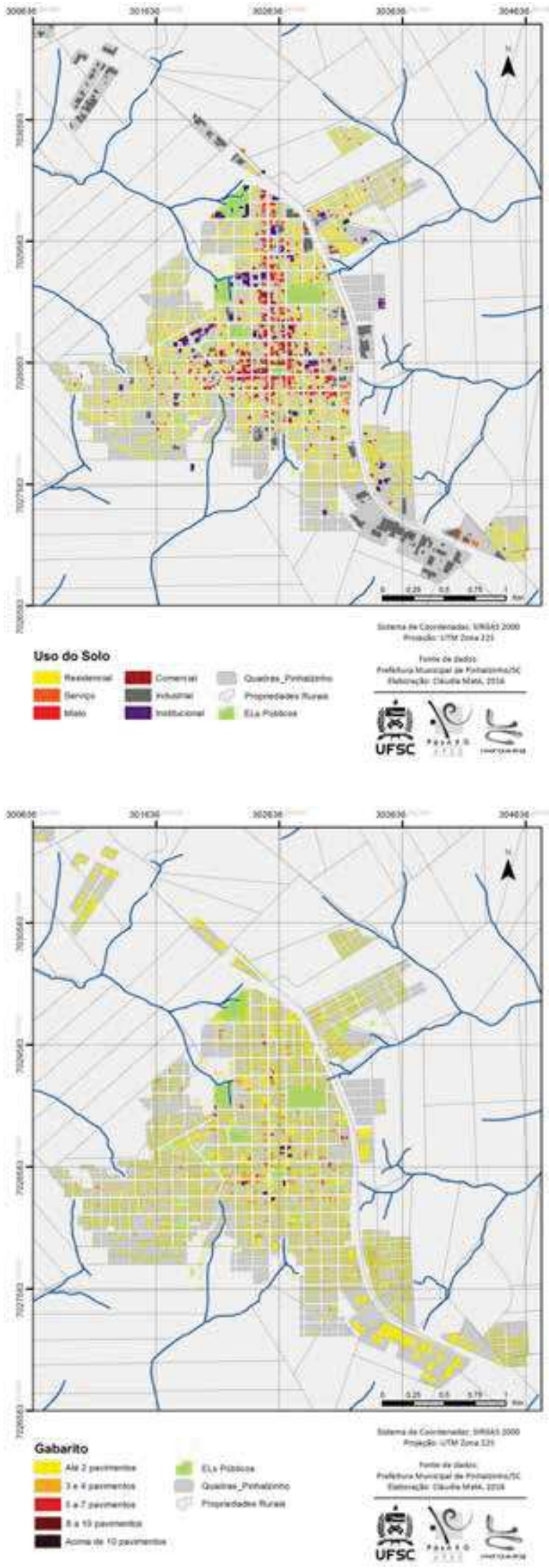

Figura 2 Mapa de Uso e Ocupação do Solo. Fonte: Elaborado por Cláudia Maté (2016)

com base no mapa cadastral e dados vetoriais da Prefeitura Municipal de Pinhalzinho (2010).
Figura 3 Mapa de Gabarito das edificações. Fonte: Elaborado por Cláudia Maté (2016) com base no mapa cadastral e dados vetoriais da Prefeitura Municipal de Pinhalzinho (2010). 
A respeito dos dados populacionais e de renda, as figuras 5 e 6 correspondem aos mapeamentos da distribuição da população residente e da renda média na cidade. A análise da população residente mostra que as maiores concentrações populacionais estão nos bairros Nova Divineia, Pioneiro e Centro, respectivamente, seguidas pelas áreas ao longo da BR-282. Já na análise da renda média, para a qual foi considerado o valor do rendimento médio mensal dos responsáveis por domićlios, verificou-se concentração de renda na área central, enquanto os bairros localizados ao leste da rodovia - Jardim Maria Terezinha, Bela Vista e Loteamento Primavera - apresentam um rendimento de até um salário mínimo. Assim, tem-se uma distribuição espacial onde a região central é mais valorizada e agrupa pessoas de maior renda, e as áreas mais periféricas abrigam pessoas menos favorecidas economicamente.

Mesmo sendo um município de pequeno porte, a análise do seu espaço urbano mostra características e problemáticas identificadas em municípios de maior porte. Entre elas, destacam-se: a distinção entre bairros associada à classe social e à localização; o início de um processo de crescimento urbano fragmentado, com abertura de loteamentos distantes da área consolidada e ao longo de rodovias; o avanço da ocupação em direção a Áreas de Preservação Permanente (APPs), muitas vezes ignorando o suporte biofísico.

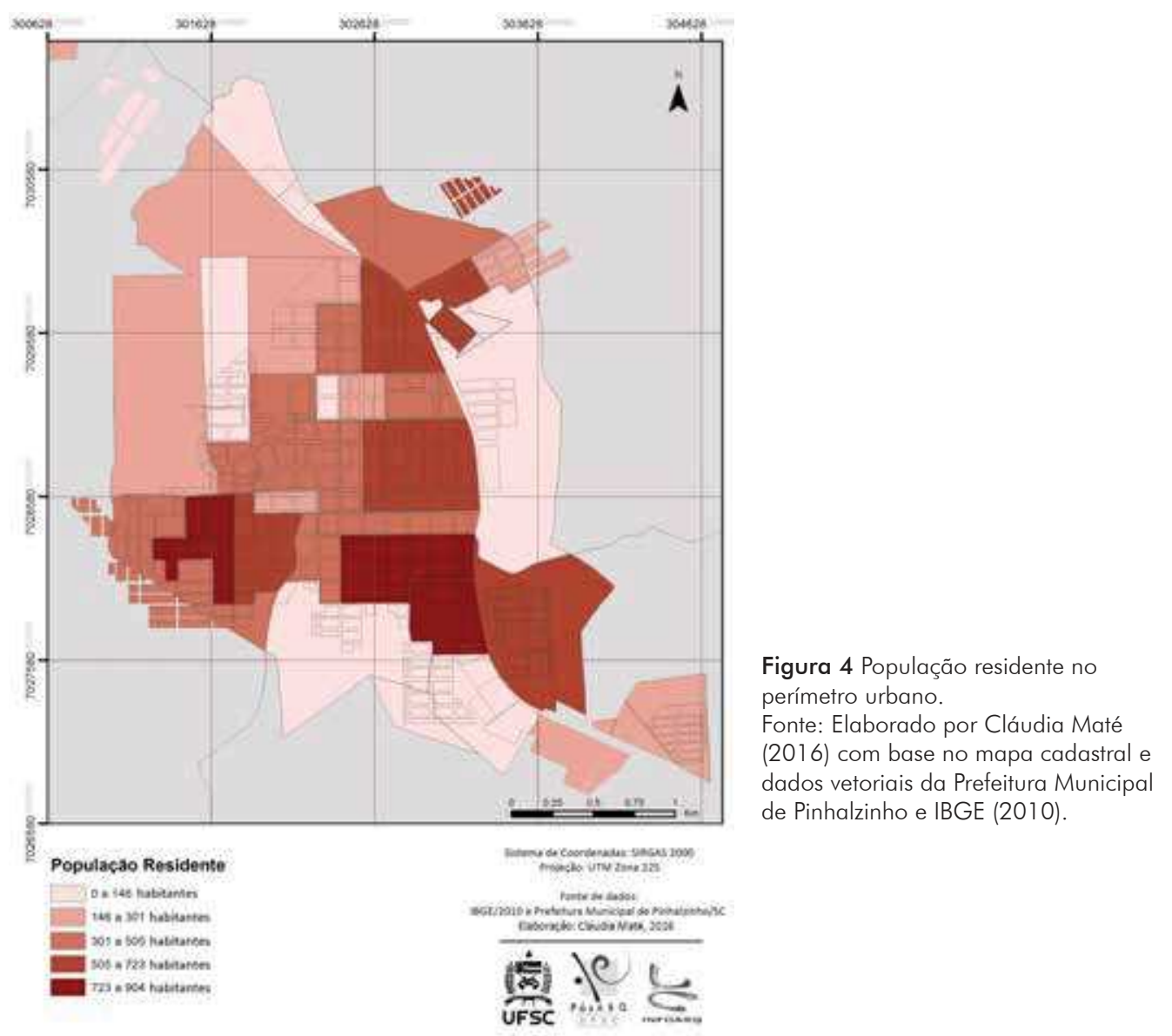




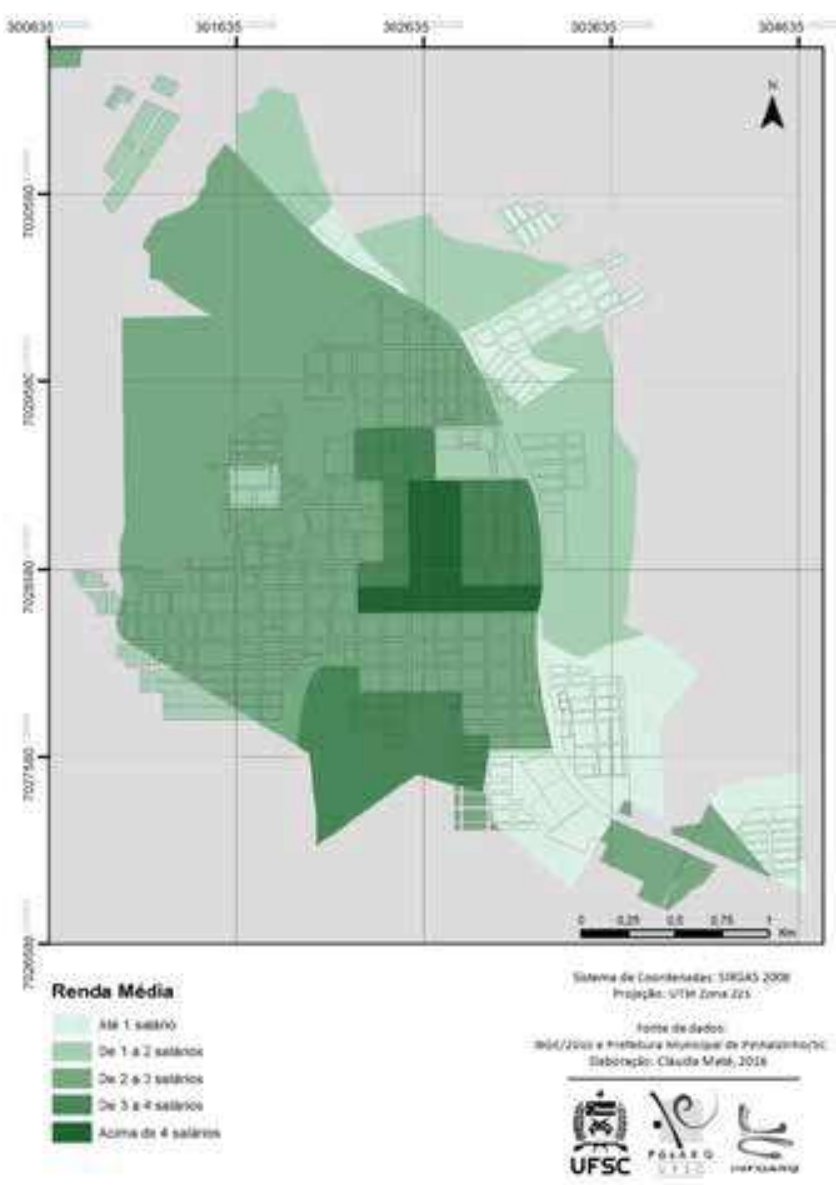

Figura 5 Renda média do perímetro urbano.

Fonte: Elaborado por Cláudia Maté (2016) com base no mapa cadastral e dados vetoriais da Prefeitura Municipal de Pinhalzinho e IBGE (2010).

\section{PROCEDIMENTOS METODOLÓGICOS}

Esta pesquisa caracteriza-se por uma abordagem qualitativa, onde o método adotado para o desenvolvimento do estudo de caso tem como referência principal os estudos dos espaços livres urbanos desenvolvidos pela Rede Nacional de Pesquisa Quapá-SEL.

A coleta de dados relativa ao espaço urbano de Pinhalzinho - especificamente as bases cartográficas, dados vetoriais (em formato shapefile) e levantamento aerofotogramétrico - foi realizada junto à Prefeitura Municipal por intermédio da Secretaria de Planejamento de Pinhalzinho. Posteriormente foi complementada e atualizada com a ajuda de levantamentos aerofotogramétricos, imagens de satélite recentes $(2015,2016)$ e observações in loco. Já os dados demográficos municipais e os dados espaciais referentes aos setores censitários municipais (também em shapefile) foram coletados por meio da sinopse do Censo 2010 (IBGE, 210).

O tratamento dos dados foi desenvolvido a partir do uso da interface do Sistema de Informações Geográficas (SIG). Primeiramente os ELPr foram identificados através da fotointerpretação e análise dos dados vetoriais municipais. Em seguida foram realizadas análises e mapeamentos relacionados à porcentagem de espaço livre intraquadra e 
verticalização por quadra nas diferentes áreas da cidade. Ambos mapeamentos foram adaptados dos estudos da Rede Quapá-SEL, com adequação dos intervalos em função do porte da cidade em estudo.

A) Mapeamento dos espaços livres intraquadra agrupados em cinco intervalos de porcentagem:

- até 30\% da quadra livre de edificações;

- de $30 \%$ a $50 \%$ da quadra livre de edificações;

- de $50 \%$ a $60 \%$ da quadra livre de edificações;

- de $60 \%$ a $70 \%$ da quadra livre de edificações;

- acima de $70 \%$ da quadra livre de edificações.

Para a análise da verticalização por quadra criou-se a categoria 'quadra não-verticalizada' - não presente nos estudos da rede, sendo, porém, a que melhor retrata a verticalização na cidade estudada. A incidência de verticalização foi considerada a partir da presença de edifícios $\geq 03$ pavimentos.

B) Mapeamento da verticalização por quadra agrupada nos seguintes intervalos: quadra não verticalizada;

- até $10 \%$ de verticalização na quadra;

- de $10 \%$ a $30 \%$ de verticalização na quadra;

- de $30 \%$ a $50 \%$ de verticalização na quadra.

Na sequência foram identificados os padrões morfológicos na cidade, o que permitiu compreender como se dá o espaço construído e o espaço livre nas diferentes áreas de Pinhalzinho. Para identificar os padrões foram cruzados e analisados os mapas temáticos desenvolvidos previamente: cheios e vazios; uso do solo; gabarito; espaços livres intraquadra; verticalização por quadra; população residente e renda média.

A partir do cruzamento dos mapas foram identificados cinco padrões. Cada um foi sistematizado em quadro descritivo contendo a síntese dos dados provenientes dos mapeamentos, a representação do padrão em cartografia e em fotografia aérea - esta obtida por intermédio de veículo aéreo não tripulado (drone) após a identificação e localização do padrão no território (quadros 1 a 5). Com a localização dos padrões na área urbana de Pinhalzinho foi elaborado o Mapa Síntese de Distribuição dos Padrões Morfológicos da cidade.

\section{RESULTADOS}

A análise dos ELPr divide-se em duas etapas: são apresentadas as análises dos espaços livres intraquadra de todo espaço urbano de Pinhalzinho, seguidas pela identificação dos padrões morfológicos no território. 
Por meio do mapa de cheios e vazios (figura 7) pode-se observar a regularidade da ocupação urbana - e também como Pinhalzinho, apesar de não possuir ampla malha urbana, já apresenta certa descontinuidade do tecido urbano. $\bigcirc$ traçado da rodovia e a forma como divide a malha urbana atual é um dos elementos que mais se destacam no mapa.

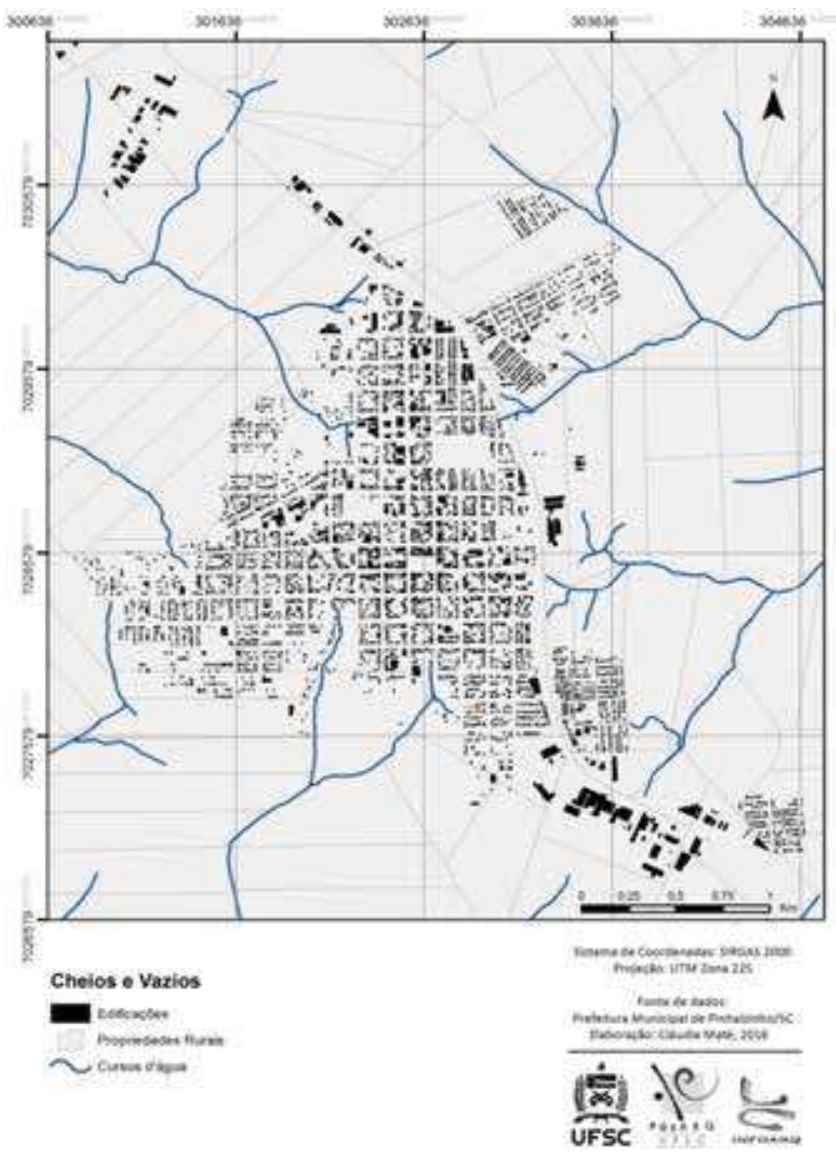

Figura 6 Mapa de cheios e vazios do perímetro urbano de Pinhalzinho. Fonte: Elaborado por Cláudia Maté (2016) com base no mapa cadastral e dados vetoriais da Prefeitura Municipal de Pinhalzinho (2010).

Quando comparada a área central com os bairros circundantes, em especial com as áreas localizadas no limite do perímetro urbano, pode-se perceber a diferença na tipologia das quadras. Na área central, que corresponde ao período inicial da ocupação, as quadras são quadradas, com as edificações próximas às ruas, conformando um miolo livre de edificações. Em relação aos demais bairros, são compostos por quadras retangulares, com lotes menores, e edificações e espaços livres reduzidos.

Na sequência realizou-se a leitura da ocupação das quadras sob dois parâmetros: a quantificação do espaço livre de edificação intraquadra e a quantificação de verticalização por quadra. Na figura 8 observa-se a porcentagem de espaços livres de cada quadra. Entre as 432 analisadas, apenas uma, no bairro Centro, possui menos de 30\% de espaço livre; 11 têm menos de 50\% de espaço livre em seu interior. A maior parte dessa quadra apresenta forma retangular e está localizada nos bairros próximos à rodovia. 


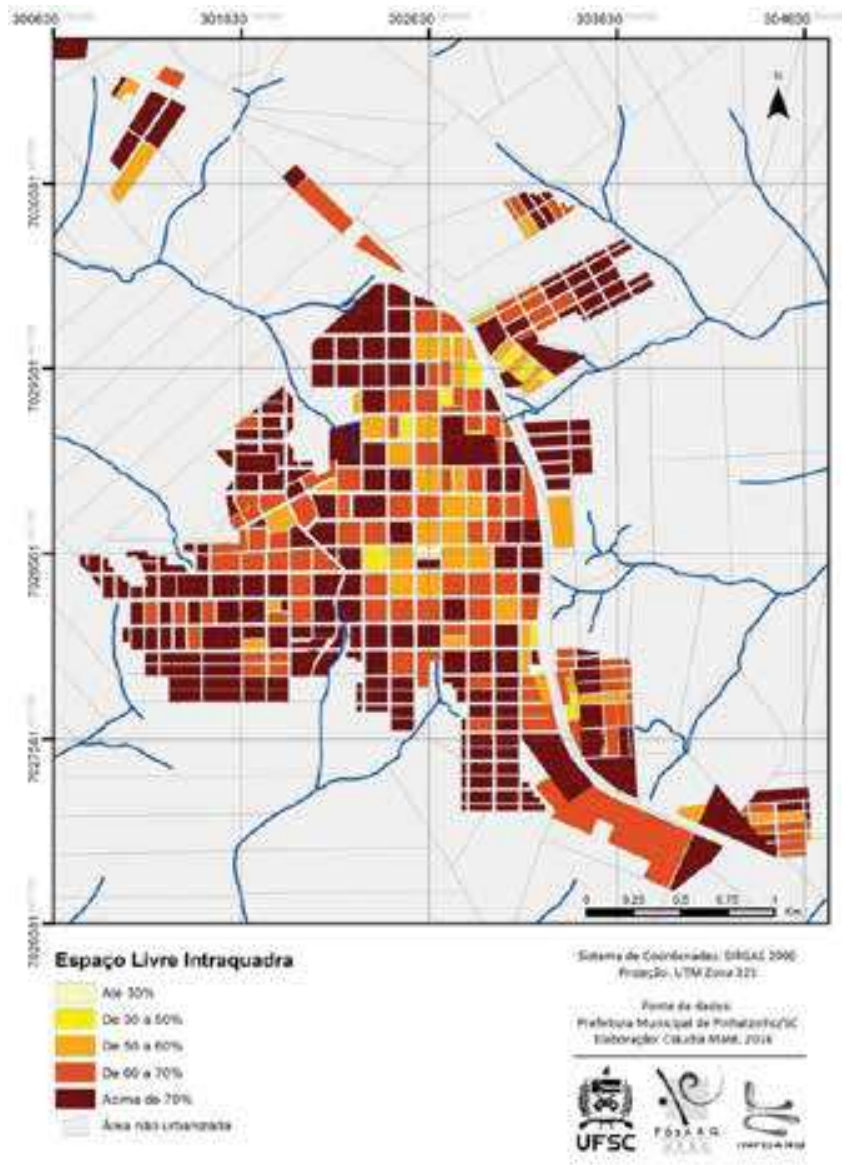

Figura 7 Mapa de espaço livre intraquadra do perímetro urbano de Pinhalzinho.

Fonte: Elaborado por Cláudia Maté (2016) com base no mapa cadastral e dados vetoriais da Prefeitura Municipal de Pinhalzinho (2010).

Os outros três intervalos são marcados por quadras com maior quantidade de terrenos não edificados. São 48 quadras com 50\% a 60\% de espaço livre, 115 com 60\% a 70\% e 255 com mais de $70 \%$ de seu espaço livre de edificação. As quadras que apresentam de 50\% a 70\% de espaço livre correspondem às áreas ocupadas nas décadas de 1970 e 1980, períodos em que houve grande crescimento populacional na cidade. A maioria dessas quadras são quadradas, com o miolo livre - e por estarem presentes em todos os bairros de Pinhalzinho, possuem os mais variados usos. Já as quadras com mais de $70 \%$ de espaço livre de edificação são majoritariamente residenciais, mais periféricas e recentes ou que contêm espaços livres públicos de recreação.

Em síntese, menos de 3\% das quadras do município possuem espaço livre intraquadra inferior a $50 \%$; $11 \%$ delas possuem entre $50 \%$ e $60 \%$, seguidas por $27 \%$ das quadras entre $60 \%$ e $70 \%$. A grande maioria delas - 59\% - apresenta mais de $70 \%$ de seu espaço intraquadra livre. Analisando esses resultados com os mais comumente encontrados nas grandes e médias cidades, observa-se grande diferença entre as cidades de portes diversos.

Enquanto nas grandes e médias cidades é observada a predominância de tecidos urbanos com no máximo 30\% de espaços livres intraquadra, em Pinhalzinho esse intervalo é praticamente inexistente. Ao mesmo tempo, as quadras com mais de $50 \%$ de espaço livre - $97 \%$ das quadras da cidade - dificilmente são encontradas nas áreas consolida- 
das dos grandes centros urbanos. Quando encontradas, são destinadas à habitação de camadas de maior renda ou porções do território em processo de consolidação, muitas vezes próximo a áreas de conservação e ocupados por população de menor renda. Diante dos resultados encontrados nesse mapeamento, pode-se concluir que a tendência de baixos índices de área livre intraquadra, comum nas grandes cidades brasileiras, não corresponde à realidade do município de Pinhalzinho.

O mapeamento da verticalização por quadra (figura 9) mostra a predominância das quadras não verticalizadas na cidade, $82 \%$ das 432 quadras analisadas. As quadras com até $10 \%$ de verticalização, ou seja, com geralmente uma ou duas edificações em altura, correspondem a 9,5\% - 36 quadras. Na sequência temos 32 quadras com 10\% a $30 \%$ de seus lotes verticalizados e apenas cinco quadras com verticalização entre $30 \%$ e $50 \%$. Juntas, correspondem a $8,5 \%$ do total municipal. Pelo mapa é possível visualizar que estão concentradas na área central e ao longo dos principais eixos viários.

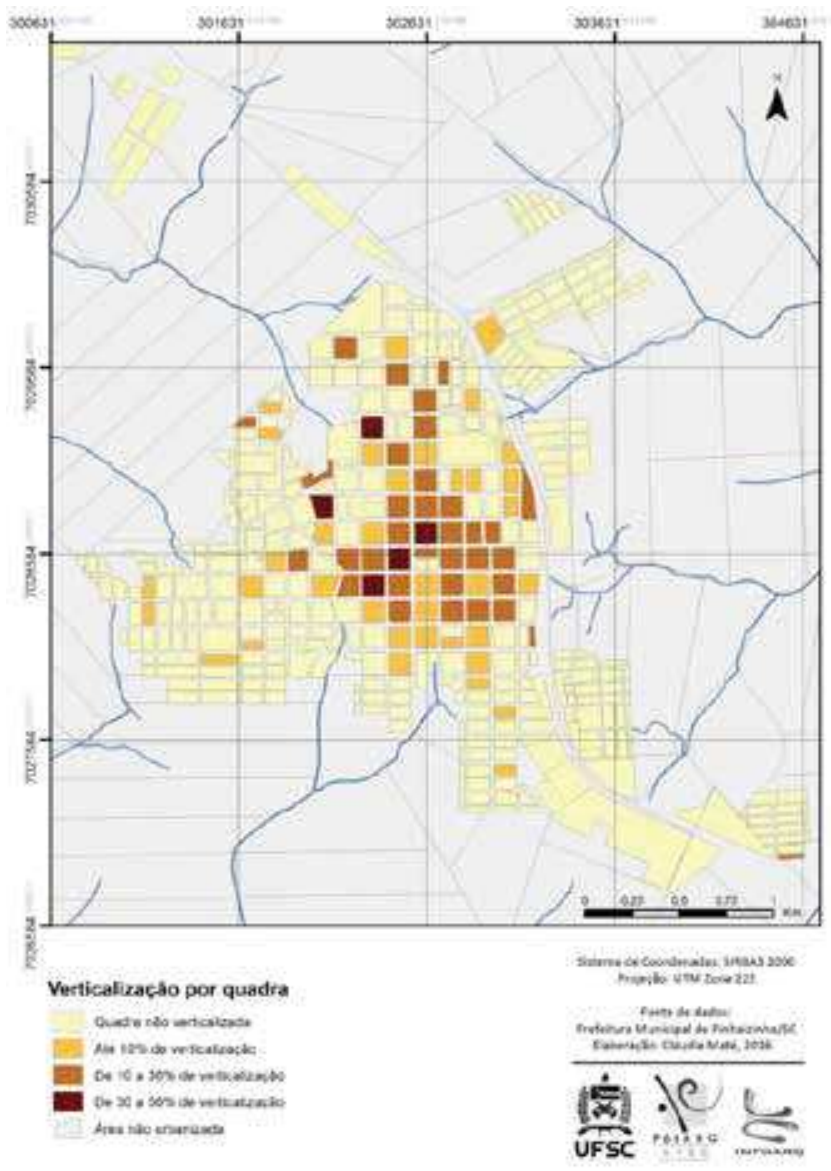

Figura 8 Mapa da verticalização de Pinhalzinho, representada pelas manchas mais escuras na área central. Nas demais áreas predominam as quadras horizontais, porém já é possível perceber a presença pontual de lotes verticalizados.

Fonte: Elaborado por Cláudia Maté (2016) com base no mapa cadastral e dados vetoriais da Prefeitura Municipal de Pinhalzinho (2010).

Com base na análise da verticalização por quadra, podemos verificar que os resultados se assemelham, em alguns aspectos, aos encontrados em grandes e médias cidades. Da mesma forma que nos municípios de maior porte, no tecido urbano de Pinhalzinho são predominantes as quadras horizontais e a concentração de quadras verticalizadas nas áreas centrais e ao longo dos principais eixos viários. Todavia, cabe 
ressaltar a grande diferença entre a intensidade da verticalização e a extensão das áreas ocupadas por esses edifícios nas grandes cidades e a realidade da verticalização pontual encontrada em Pinhalzinho, onde nenhuma quadra possui mais de $50 \%$ dos seus lotes verticalizados.

Ao relacionarmos os dois mapeamentos, verifica-se que as quadras que possuem maiores taxas de espaços livres intraquadra também são as que apresentam menores taxas de verticalização e predominância de uso residencial. Por outro lado, as poucas quadras mais verticalizadas, ocupadas em sua maioria por edifícios mistos, possuem menor quantidade de espaço livre.

Diante desses resultados e do entendimento geral da quantidade de espaços livres intraquadra e intensidade da verticalização no espaço urbano de Pinhalzinho, realizou-se a análise na escala da quadra urbana através da identificação dos padrões morfológicos. Essa identificação tem a finalidade de compreender a relação entre espaço livre e espaço construído que condiciona a forma de ocupação das quadras e seu reflexo nas tipologias e distribuição dos espaços livres privados encontrados em Pinhalzinho.

O Padrão Morfológico 01 é caracterizado por apresentar as quadras com menores dimensões - consequentemente, os lotes de tamanho mais reduzido quando comparados aos demais padrões. Esse padrão compreende as áreas de menor poder aquisitivo, os bairros mais afastados da região central, inclusive os localizados na porção leste da rodovia (quadro 1).

\section{Quadro 1 Padrão Morfológico 01}

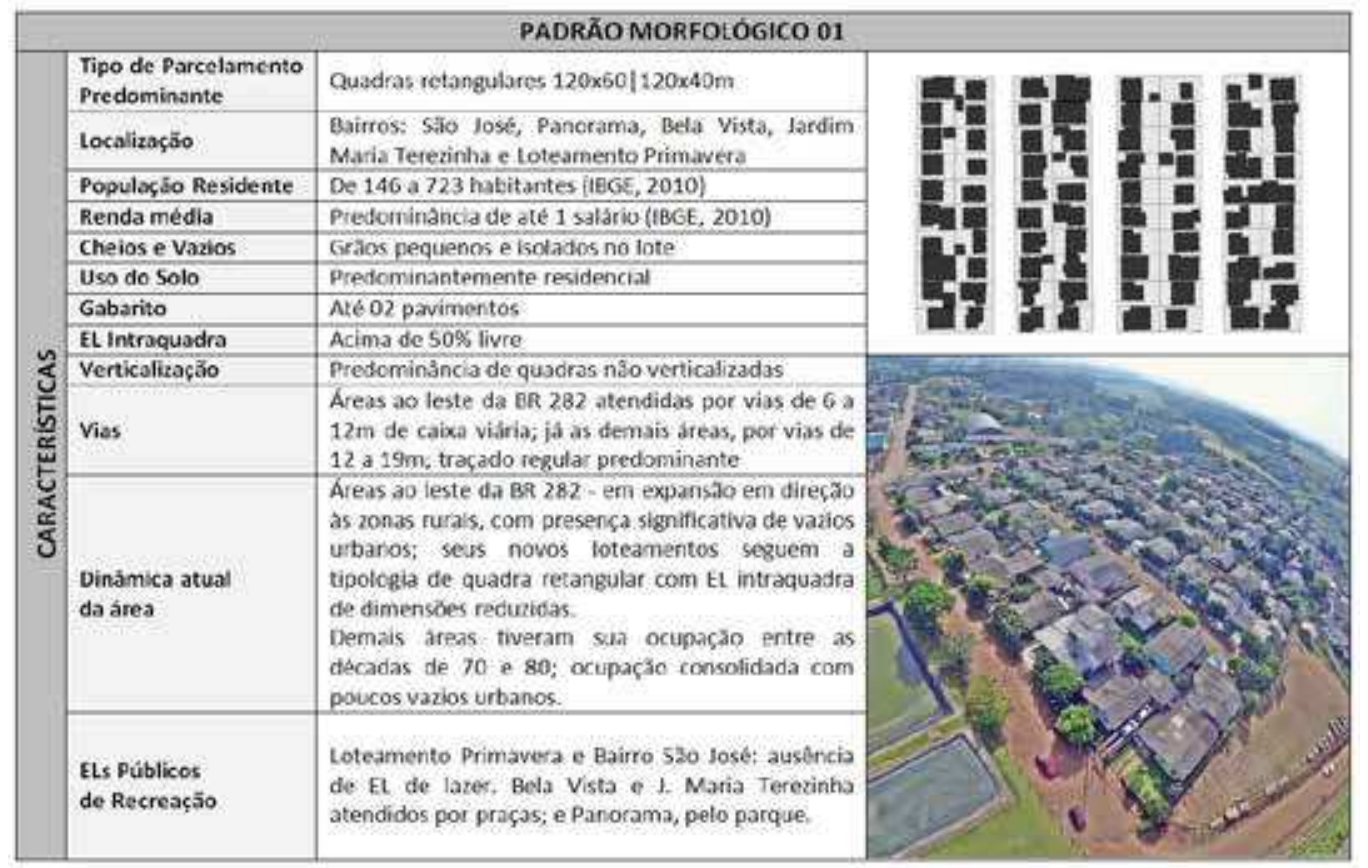

Fonte: Cláudia Maté (2016). 
Ao comparar os padrões 01 e 02 , verificam-se semelhanças quanto à morfologia das quadras e forma de ocupação do lote, com edificações isoladas e, em sua maioria, pequenas e de uso residencial. No entanto, a diferença encontra-se na renda média dos habitantes, que resulta em diversas tipologias de edificação e de espaço livre privado; na verticalização, já que o Padrão 01 possui apenas edificações de até dois pavimentos - e o Padrão 02 engloba áreas com verticalização pontual; nas vias de acesso - de maior caixa viária e melhor infraestrutura no segundo padrão; na localização, iá que o primeiro padrão abrange os bairros localizados ao leste da BR-282 e o segundo corresponde a áreas mais próximas da região central. A comparação entre quadras de ambos padrões pode ser vista nas figuras 10 e 11.

Quadro 2 Padrão Morfológico 02

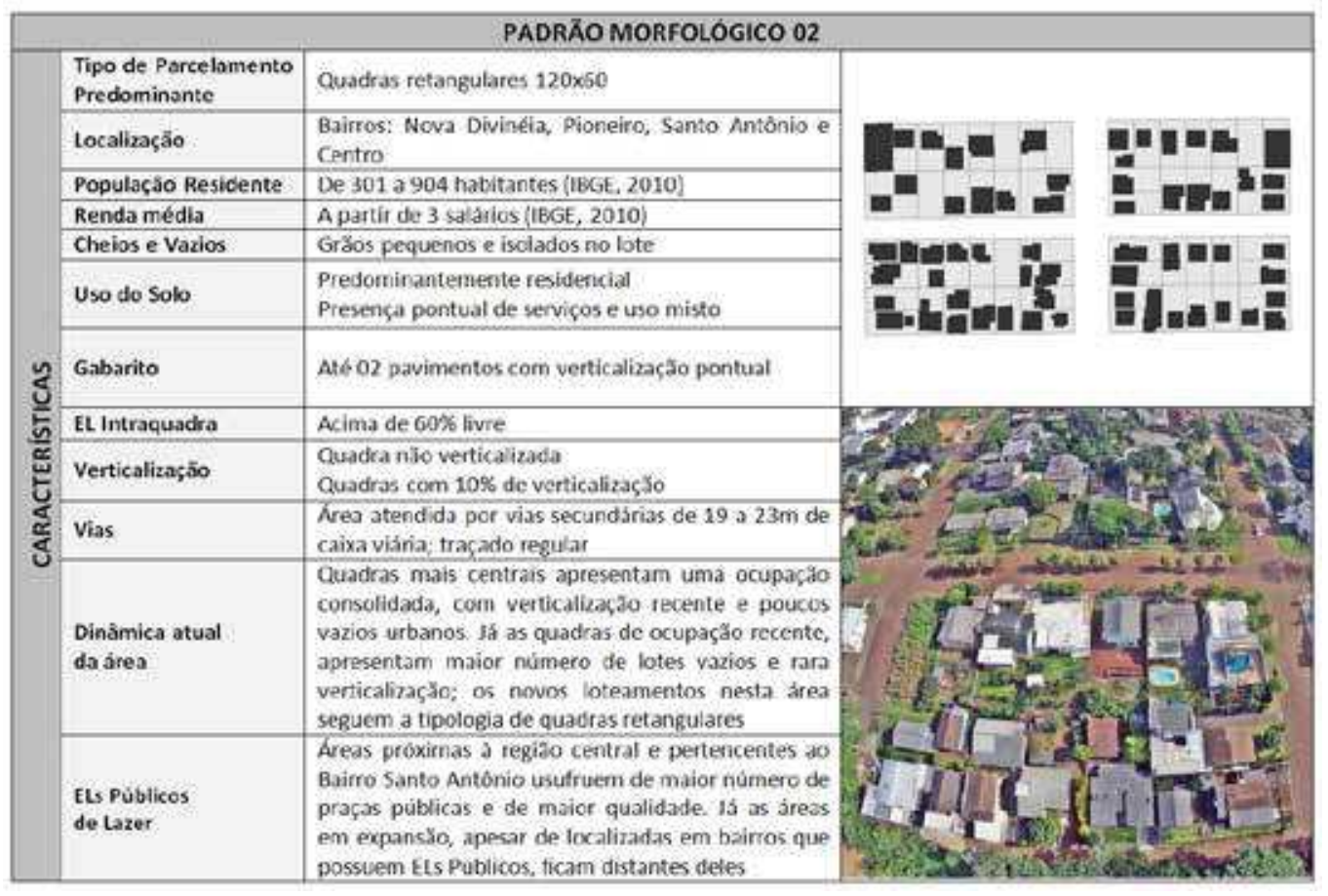

Fonte: Cláudia Maté (2016).

As áreas em expansão de ambos padrões seguem a tipologia de quadras retangulares, como pode ser visto nas figuras 12 e 13. Nas quadras do Padrão 02 pode-se verificar que a mancha urbana é menos consolidada, resultando em grande incidência de lotes não edificados (figura 14), muitos ocupados com cultivos. 


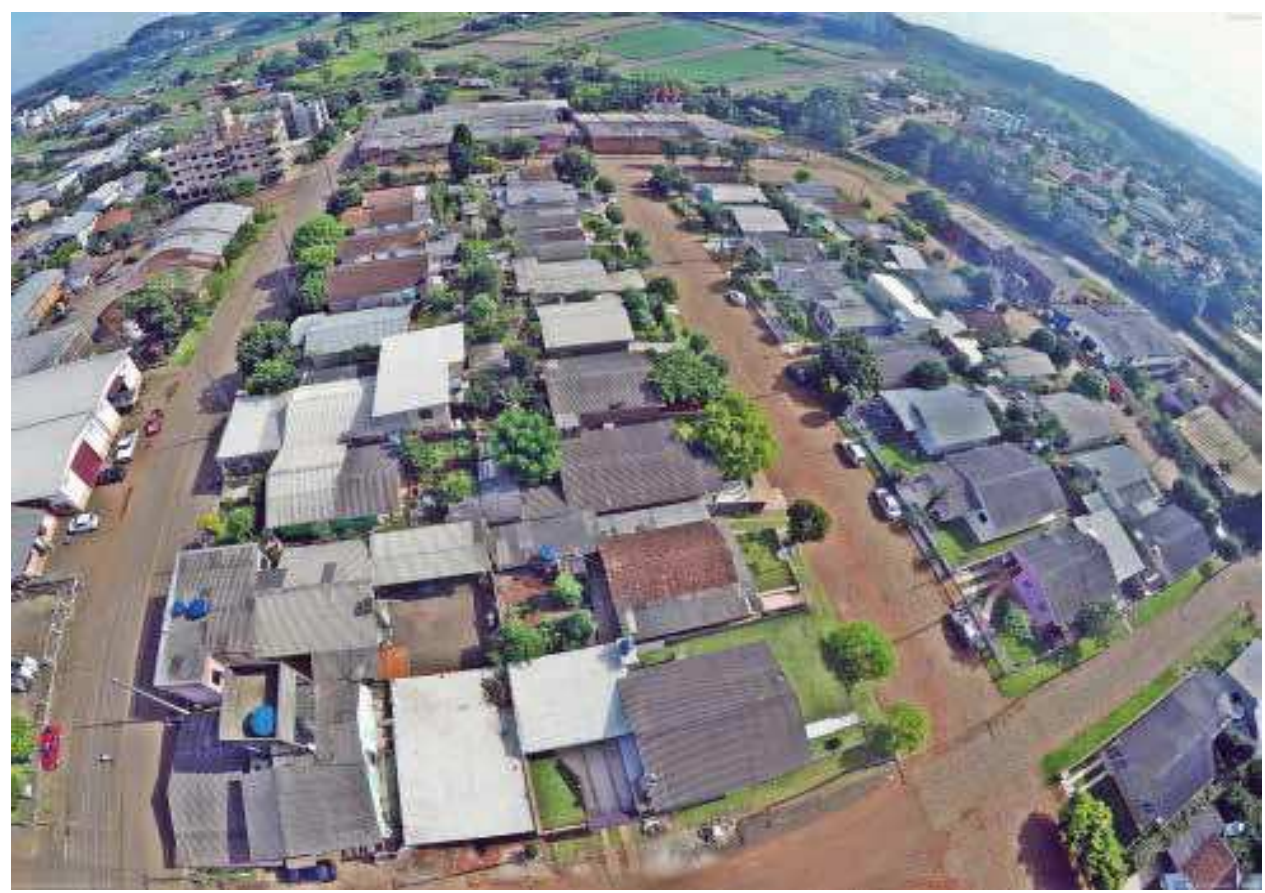

Figura 9 Padrão 01 - Bairro São José.

Fonte: Arquivo pessoal, 2016.

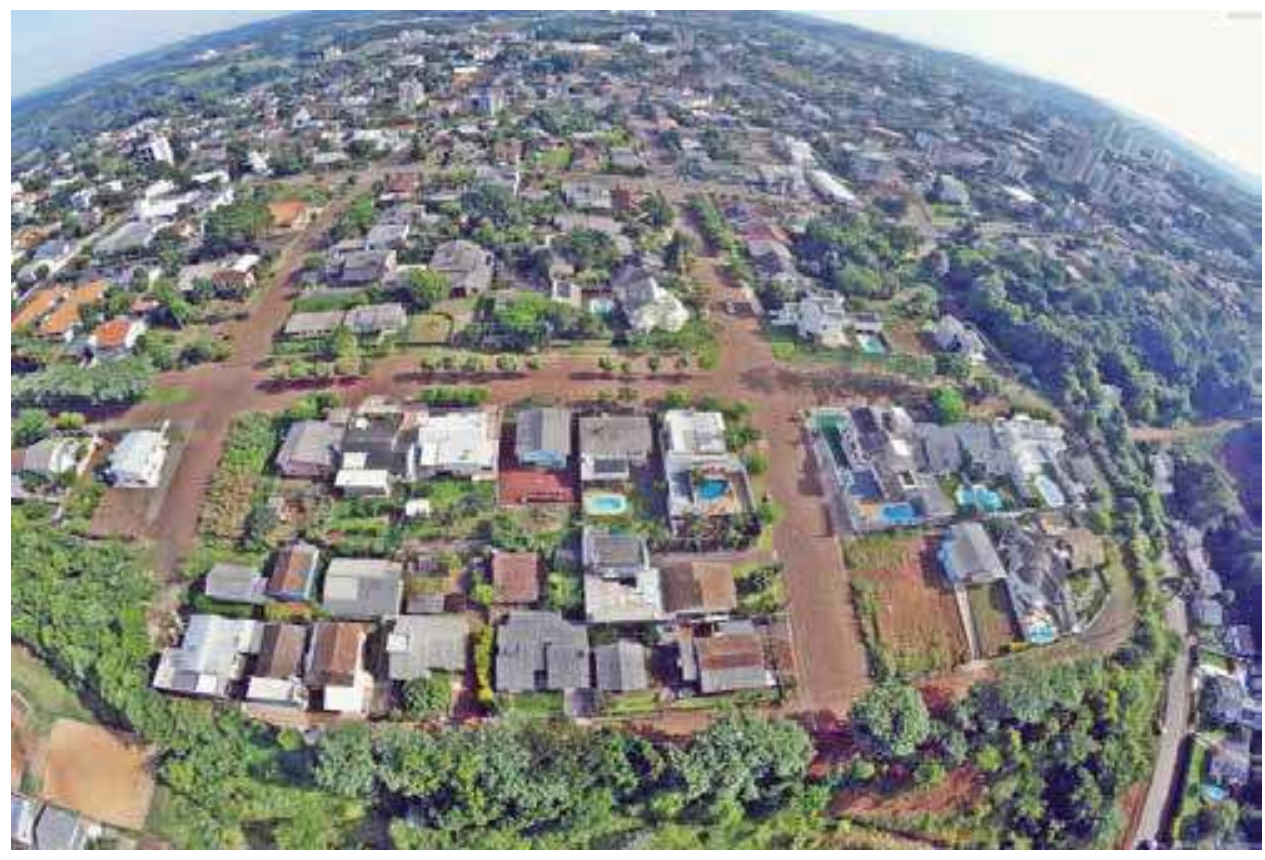

Figura 10 Padrão 02 - Bairro Pioneiro.

Fonte: Arquivo pessoal, 2016. 


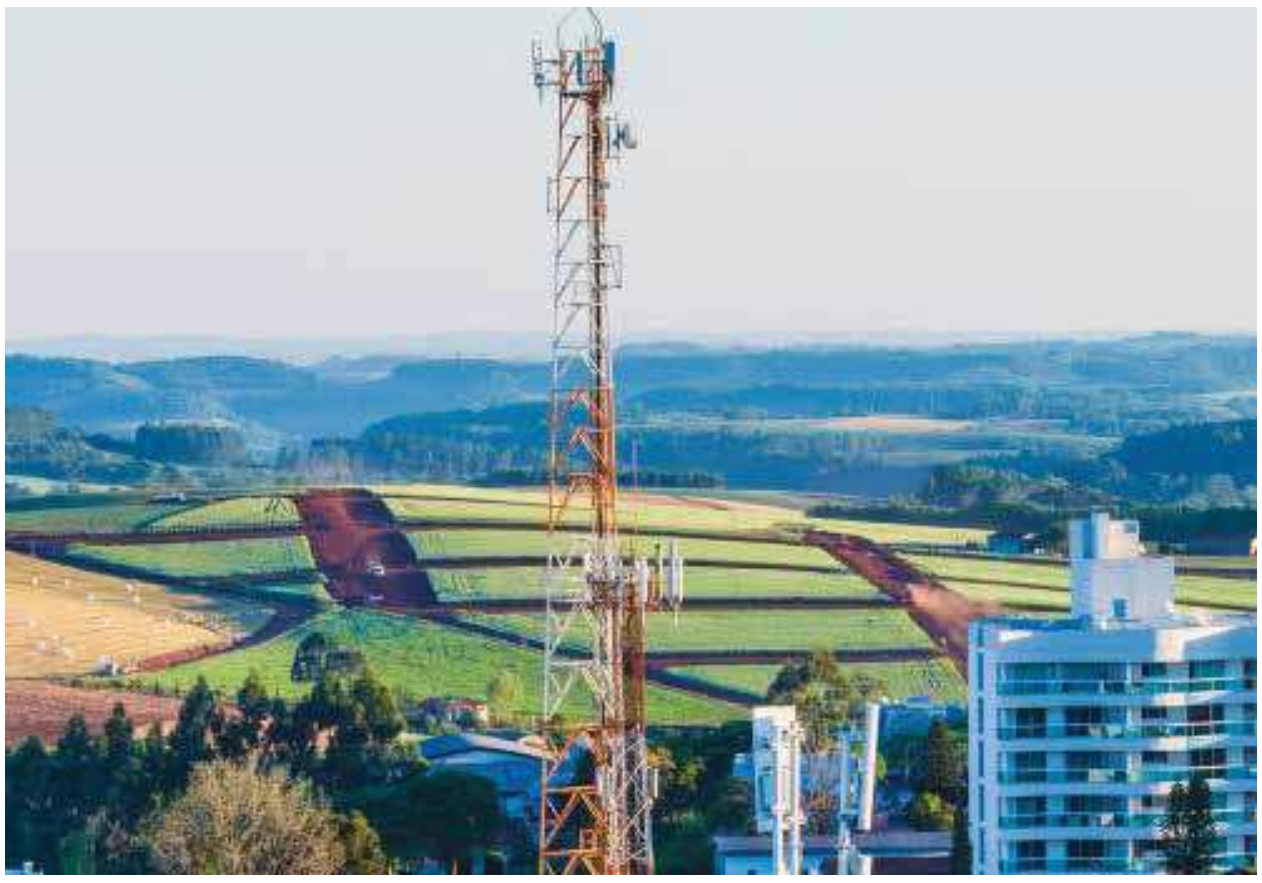

Figura 11 Área em expansão - Bairro Nova Divineia. Fonte: Arquivo pessoal, 2016.

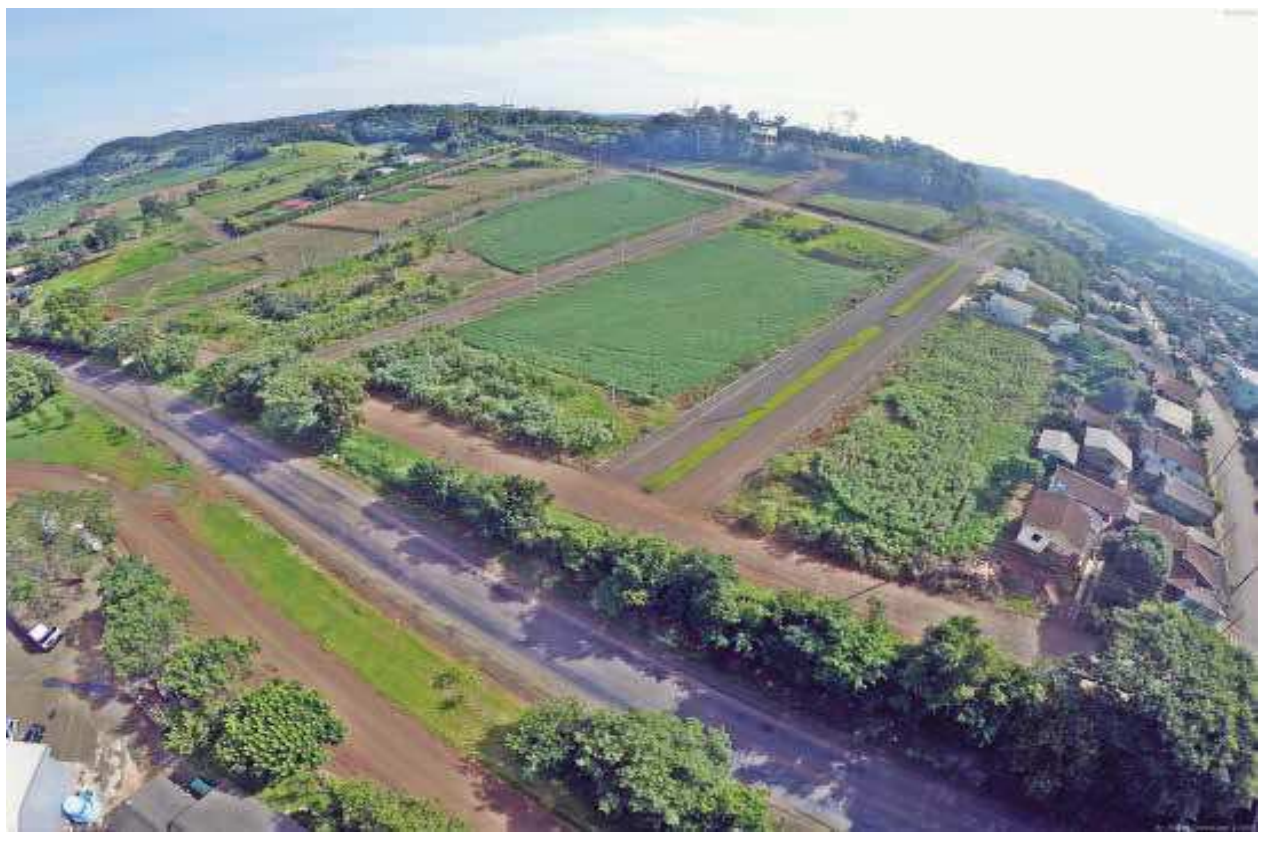

Figura 12 Loteamento - Bairro Bela Vista. Fonte: Arquivo pessoal, 2016. 


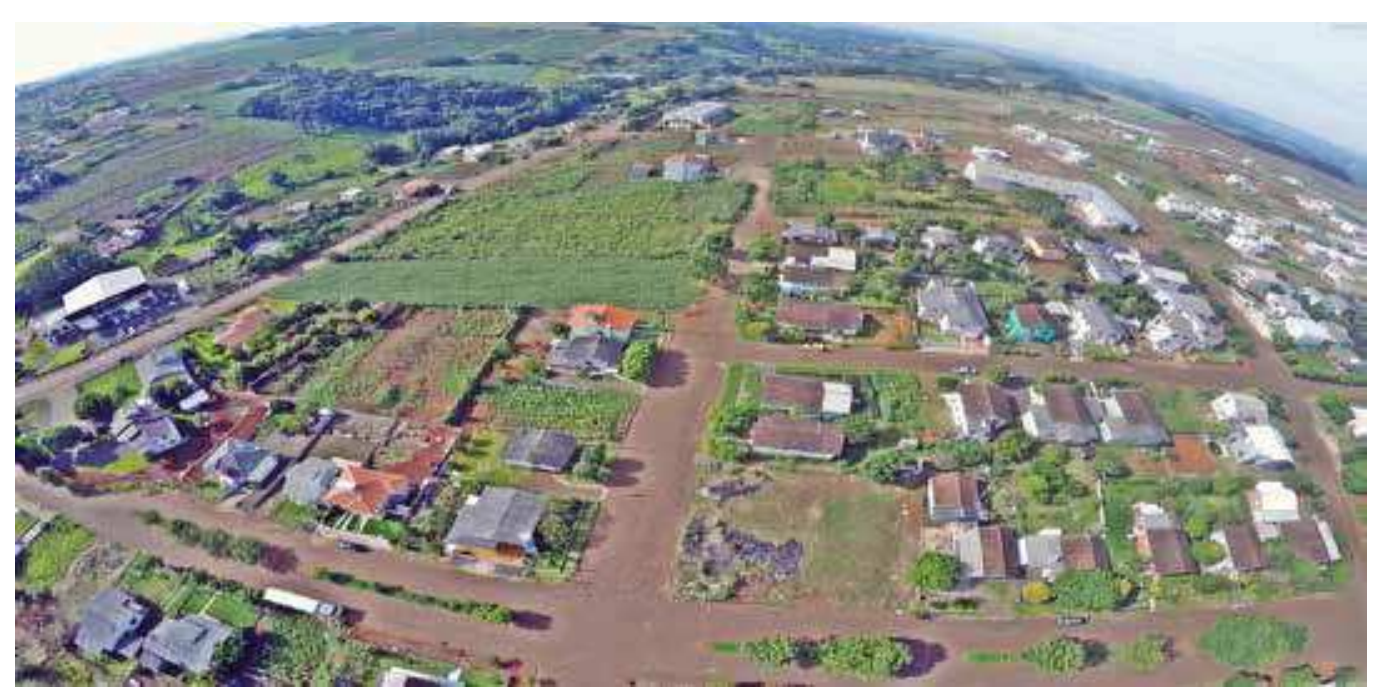

Figura 13 Padrão 02 - Mancha urbana menos consolidada no bairro Pioneiro. Fonte: Arquivo pessoal, 2016.

Nas quadras do Padrão 03, predomina a ocupação residencial e horizontal com verticalização pontual. Diferente dos padrões anteriores, essas quadras apresentam configuração quadrada e maiores dimensões - portanto os espaços livres privados intraquadra são abundantes, arborizados, de usos diversificados. Pode-se dividir as quadras desse padrão em dois grupos, de acordo com localização, renda e a resultante tipologia de espaço livre privado. Nas áreas de maior poder aquisitivo, são comuns áreas de lazer privadas com jardins, piscinas, decks, e, consequentemente, maior impermeabilização do solo. Já nas áreas de renda inferior, as áreas verdes ocupam maior parte do lote, com presença de pomares e hortas (figuras 15 e 16).

Como pode ser observado nas figuras 15 e 16, a forma e dimensão dessas quadras garante um miolo livre de edificações. Essa característica é presente nos Padrões 03 e 04, especialmente na área central e arredores, de ocupação mais antiga. A diferença entre os padrões consiste na dimensão das edificações e na forma como ocupam o lote. Nas quadras do Padrão 03, as edificações são predominantemente residenciais, configurando grãos pequenos e isolados no lote. No Padrão 04 - onde há uso comercial, misto e de serviço -, as taxas de ocupação dos lotes são maiores, com recuos frontais e laterais reduzidos ou inexistentes.

O Padrão 04 também compreende as áreas com maior incidência de verticalização na cidade. Mesmo possuindo poucos edifícios com mais de oito pavimentos, é possível perceber o efeito da verticalização nos espaços livres privados dessas quadras. Os lotes onde se localizam esses edifícios apresentam maior impermeabilização do solo, não possuem áreas vegetadas e, principalmente na área central, têm altas taxas de ocupação. Os edifícios com 14 e 16 pavimentos ocupam praticamente a totalidade do lote e as porções livres são pavimentadas e usadas para estacionamento (figura 17). 
Quadro 3 Padrão Morfológico 03

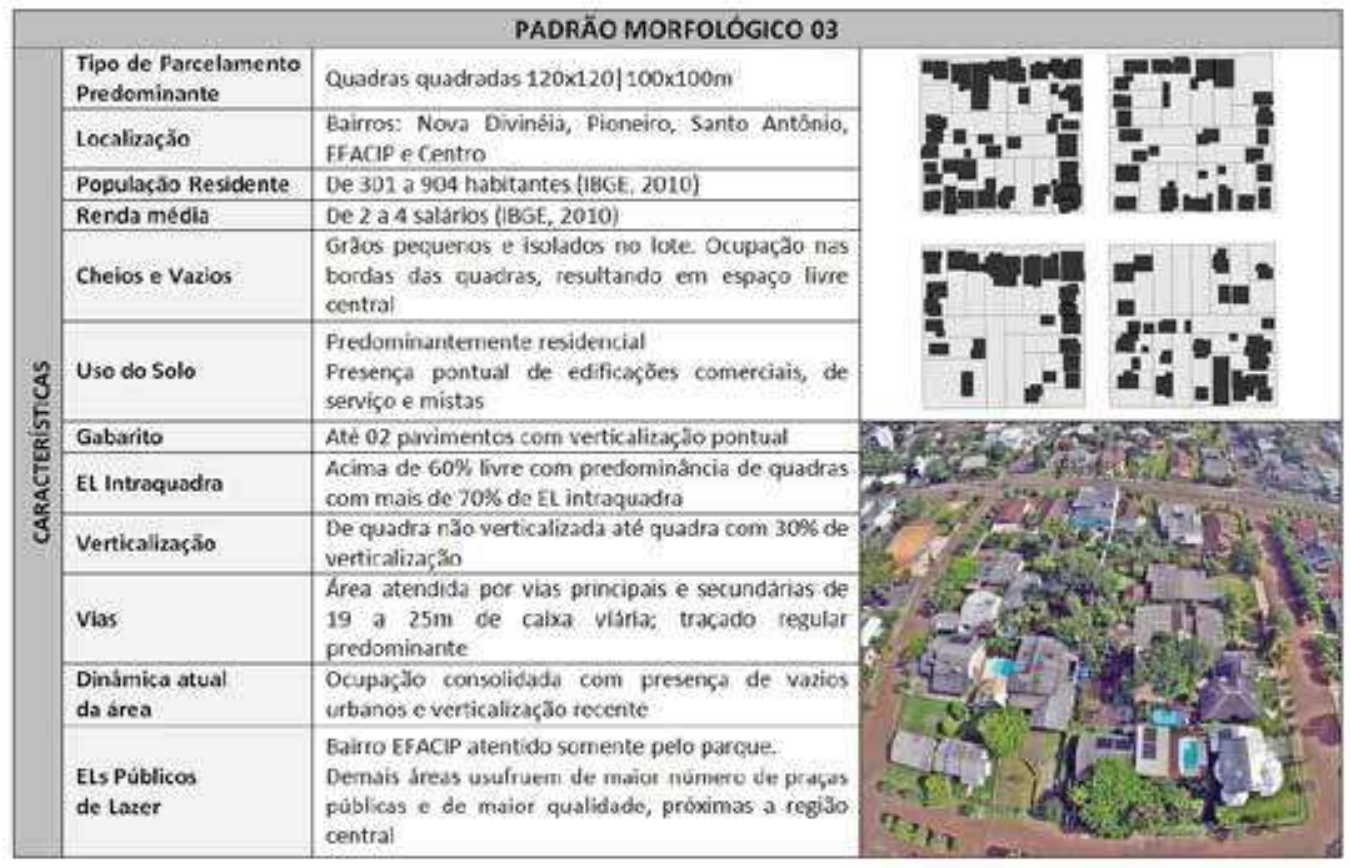

Fonte: Cláudia Maté (2016).

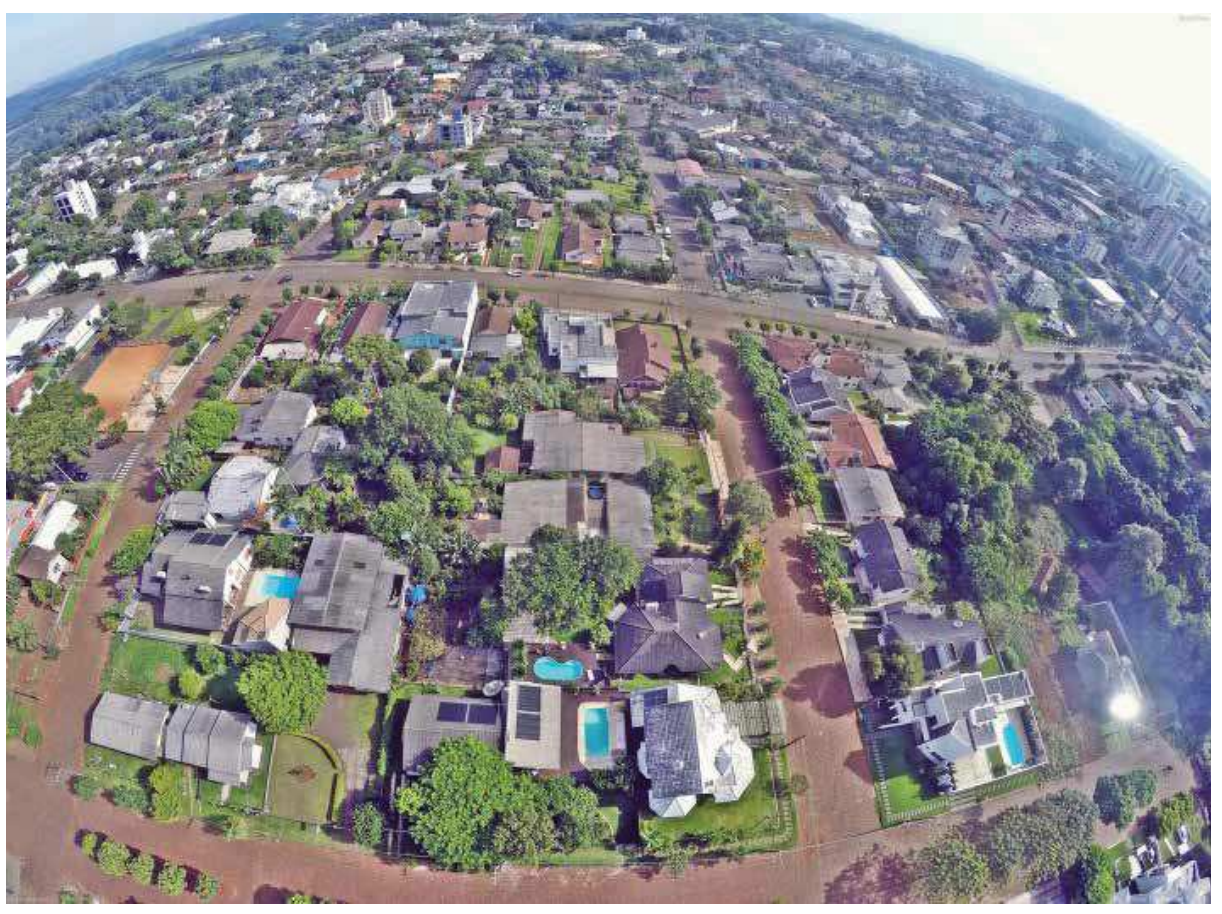

Figura 14 Padrão 03 - Bairro Pioneiro.

Fonte: Arquivo pessoal, 2016. 


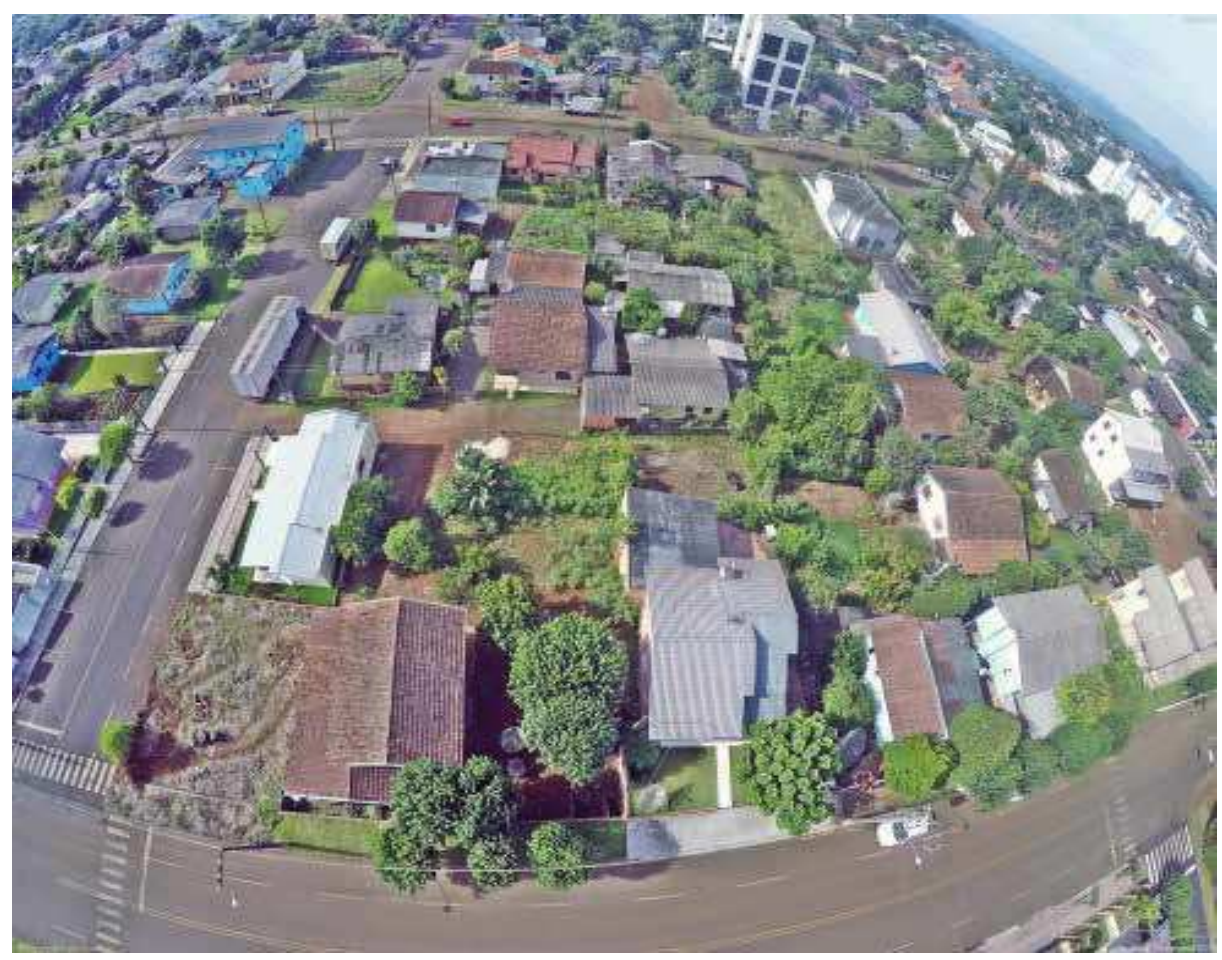

Figura 15 Padrão 03 - Bairro Nova Divineia.

Fonte: Arquivo pessoal, 2016.

Quadro 4 Padrão Morfológico 04

\begin{tabular}{|c|c|c|c|}
\hline \multicolumn{4}{|c|}{ PADRAO MORFOLOGICO 04} \\
\hline \multirow{12}{*}{ 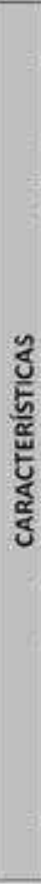 } & $\begin{array}{l}\text { Tipo de Parcelamento } \\
\text { Predominante }\end{array}$ & Quadras quadradas $120 \times 120$ & \\
\hline & Localizaçã̃o & $\begin{array}{l}\text { Ao longo dos eixos da Av, Brasilia e Av. Porto Alegre, } \\
\text { cortando os bairros EFACIP, SFo loso, Centro, Pioneiro } \\
\text { e Nova Divineis }\end{array}$ & \\
\hline & Populaşio Residente & De 116 a 904 habitantes (18GE, 2010 ) & \\
\hline & Renda média & A partir de 3 salários (1BGE, 2010) & \\
\hline & Cheios e Vazios & $\begin{array}{l}\text { Gralos maiores e isolados no lote. Em edificaçoes } \\
\text { comerdais e edifióos verticais, diminuiçăo dos } \\
\text { afastamentos laterais e ausência de recuos frontais. } \\
\text { Ooupacăo nas bordas das quadras, resultando em } \\
\text { espaco livre centrat. }\end{array}$ & \\
\hline & Uso do Solo & Comercial, Servico, Misto e Residencial & \\
\hline & Gabarito & $\begin{array}{l}\text { Area com maior incidência de verticolizajajo - sté } 16 \\
\text { pavimentos, porem pontual. Predeminam as } \\
\text { edificaçoos com ate } 02 \text { pavimentos }\end{array}$ & \\
\hline & EL intraquadra & $\begin{array}{l}\text { Abrange a ánica quadra com ate } 30 \% \text { livre do } \\
\text { municipio. Prodominio de quadras com } 30 \text { a } 60 \text { s livre }\end{array}$ & \\
\hline & Verticalicasăo & $\begin{array}{l}\text { De quadra nāo verticalizada até quadra com } 505 \text { de } \\
\text { verticalizaçāe; }\end{array}$ & \\
\hline & Vies: & $\begin{array}{l}\text { Area atendida por vias principais de } 23 \text { e } 25 \mathrm{~m} \text { de caixa } \\
\text { vídria; traçado regular predominante }\end{array}$ & \\
\hline & $\begin{array}{l}\text { Dinàmica atual } \\
\text { da área }\end{array}$ & 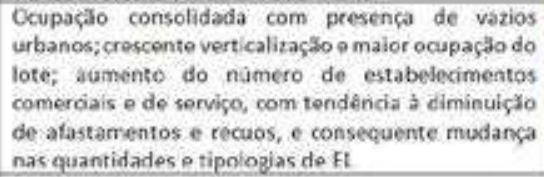 & If \\
\hline & $\begin{array}{l}\text { ELs Públicos } \\
\text { detazer }\end{array}$ & $\begin{array}{l}\text { Todas as areas atendidas por praças e parcues - } \\
\text { proximidade aos eixos principais }\end{array}$ & $\mathrm{SO}^{2} \mathrm{x}^{2}$ \\
\hline
\end{tabular}

Fonte: Cláudia Maté (2016). 
Ressalta-se que, apesar de ocupadas por edificações maiores, essas quadras ainda apresentam significativo espaço livre central. Como ainda não existem quadras com mais de $50 \%$ de seus lotes verticalizados, as quadras desse padrão apresentam áreas verdes e permeáveis relacionadas aos lotes das edificações horizontais. A ocupação de uma dessas quadras é ilustrada na figura 18, na qual é possível verificar como os edifícios ocupam a maior parte dos lotes onde estão inseridos e como os poucos espaços livres vegetados nesta quadra estão ligados ao uso residencial.

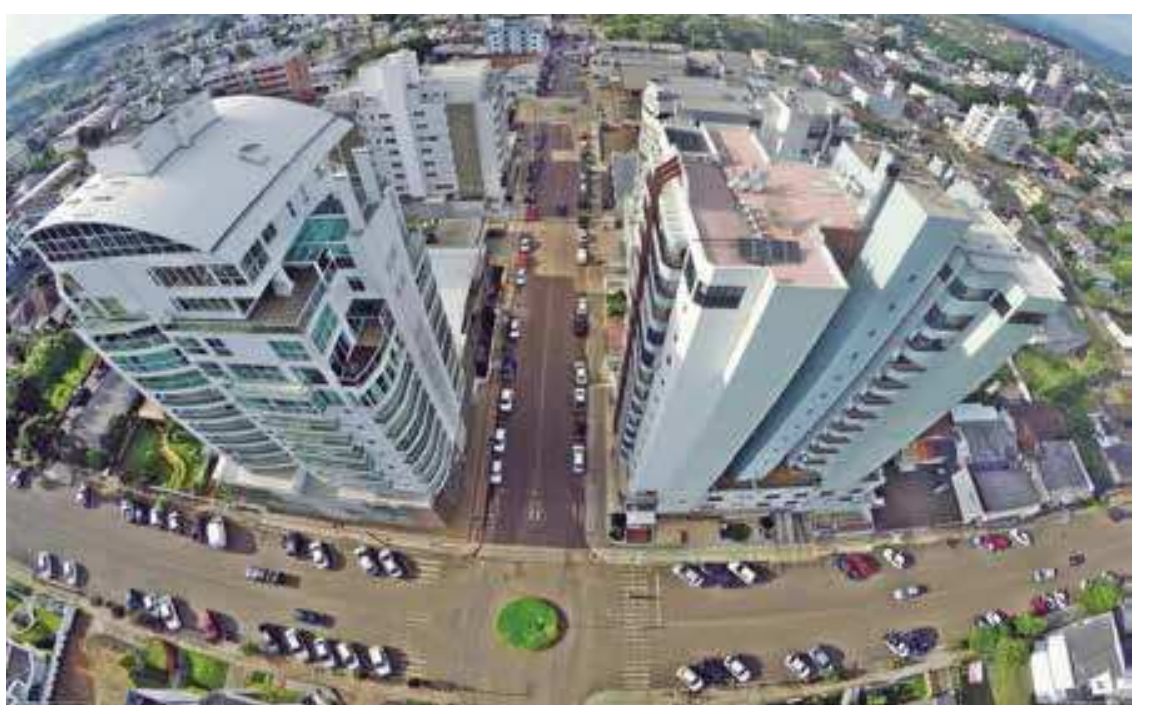

Figura 16 Verticalização na área central.

Fonte: Arquivo pessoal, 2016.

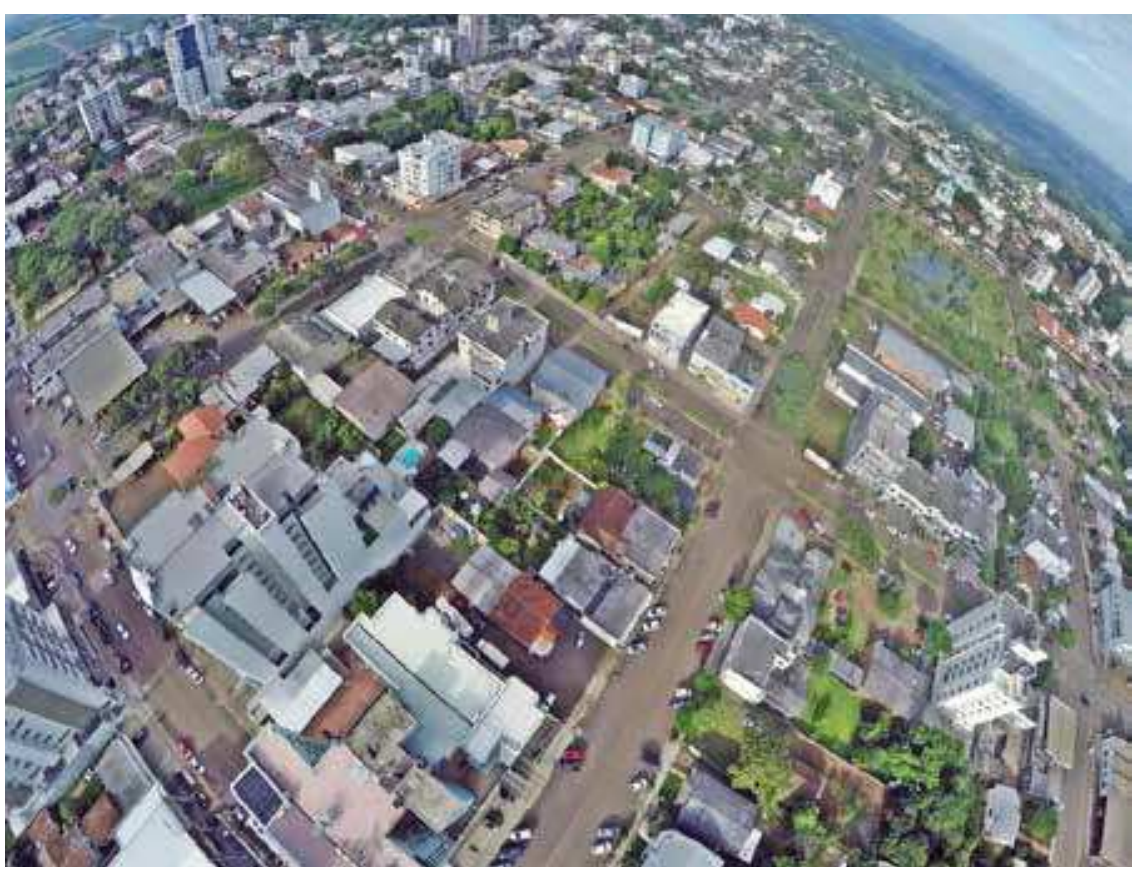

Figura 17 Padrão 04 - Ocupação da quadra. Fonte: Arquivo pessoal, 2016. 
O padrão Morfológico 05 é caracterizado por grandes edificações, de uso industrial, institucional ou comercial de grande porte que ocupam grande parte dos lotes. As quadras apresentam formas e dimensões variadas e são encontradas em diferentes bairros e ao longo da BR-282. Nos bairros centrais, a predominância é de uso institucional e comercial, enquanto as quadras localizadas mais próximas da rodovia, inclusive os grandes lotes ao longo dela, são ocupadas por indústrias.

O uso industrial e comercial presente nessas quadras conferem altos índices de impermeabilização do solo e escassez de vegetação. Nessas áreas são encontrados os espaços livres intraquadra mais pavimentados, a exemplo de depósitos, pátios de indústrias, postos de combustível e, em maior número, estacionamentos (figura 19). Já nas quadras institucionais, apesar da grande ocupação do lote, os espaços livres geralmente são vegetados e permeáveis (figura 20).

Quadro 5 Padrão Morfológico 05

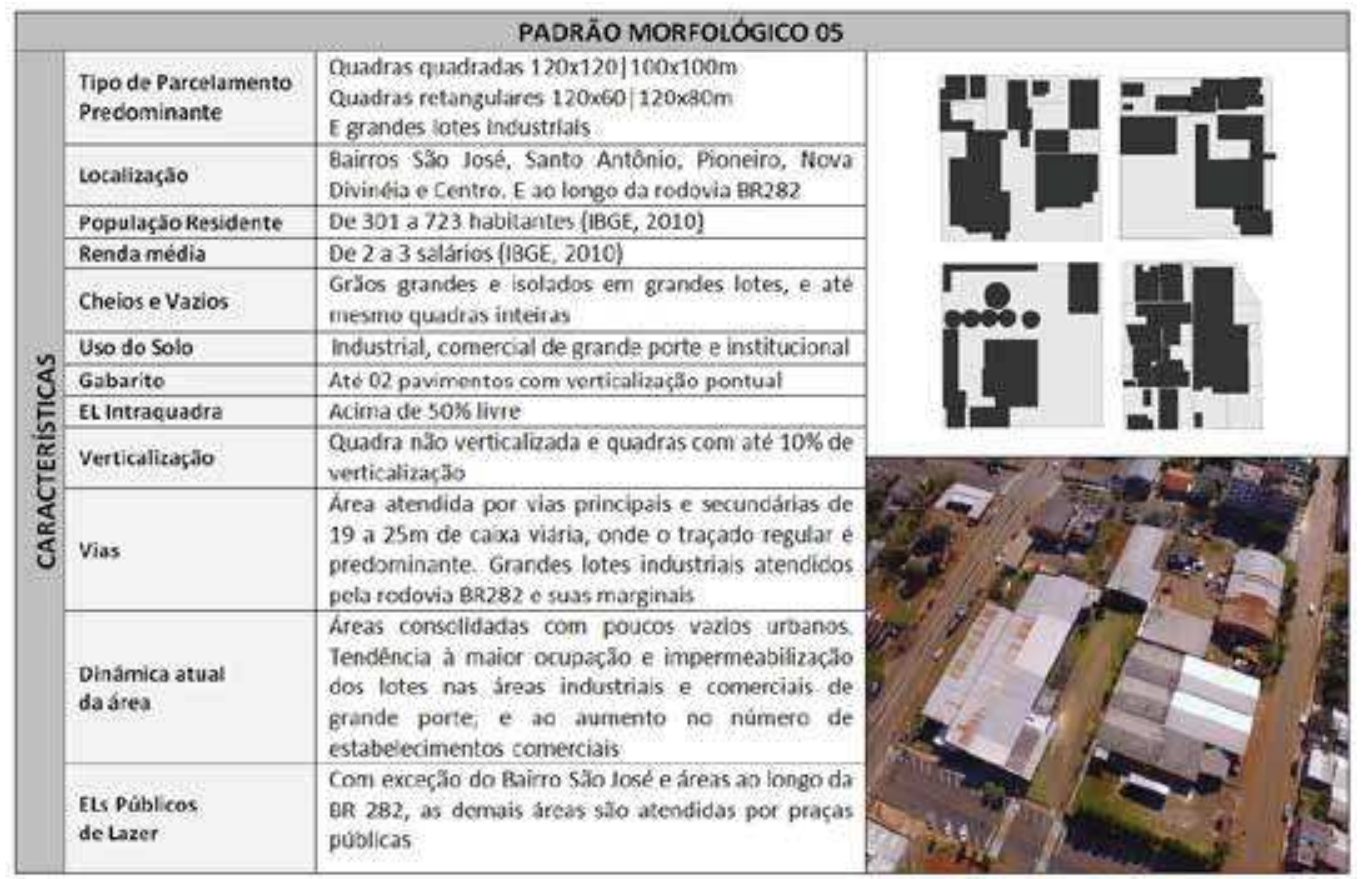

Fonte: Cláudia Maté (2016).

Através da identificação dos cinco padrões morfológicos, foi possível compreender a influência dos diferentes aspectos analisados sobre a forma de ocupação das quadras e a ocupação da totalidade do espaço urbano. De forma geral, Pinhalzinho é composto por cinco tipos de quadras - com diferentes perfis de construção e de espaços livres, com predominância de quadras horizontais em áreas residenciais consolidadas ou em processo de consolidação nos diferentes bairros - e possui tendência a quadras mais verticalizadas em áreas mais valorizadas, no Centro e arredores. Cabe acrescentar a 
influência dos eixos viários na ocupação das quadras por toda sua extensão, onde é verificada a tendência a maior ocupação do lote, a substituição de residências por usos comerciais e de serviço e a crescente verticalização.

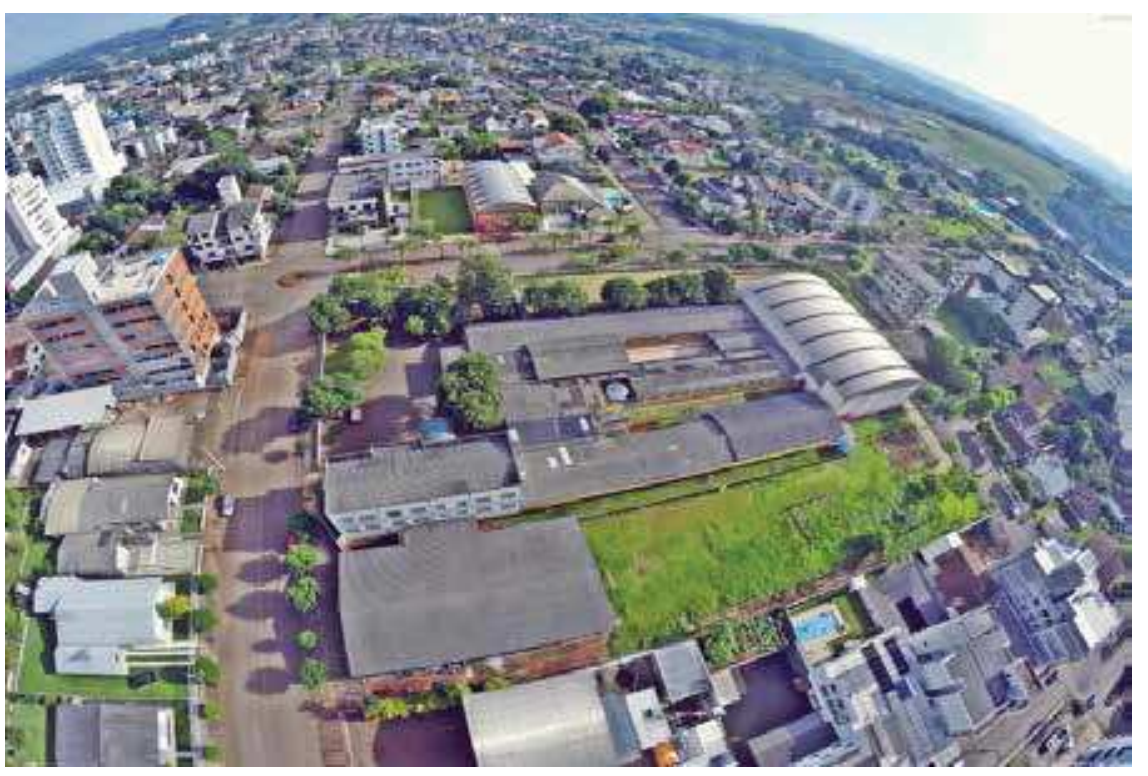

Figura 18 Colégio Estadual no bairro Centro. Fonte: Arquivo pessoal, 2016.

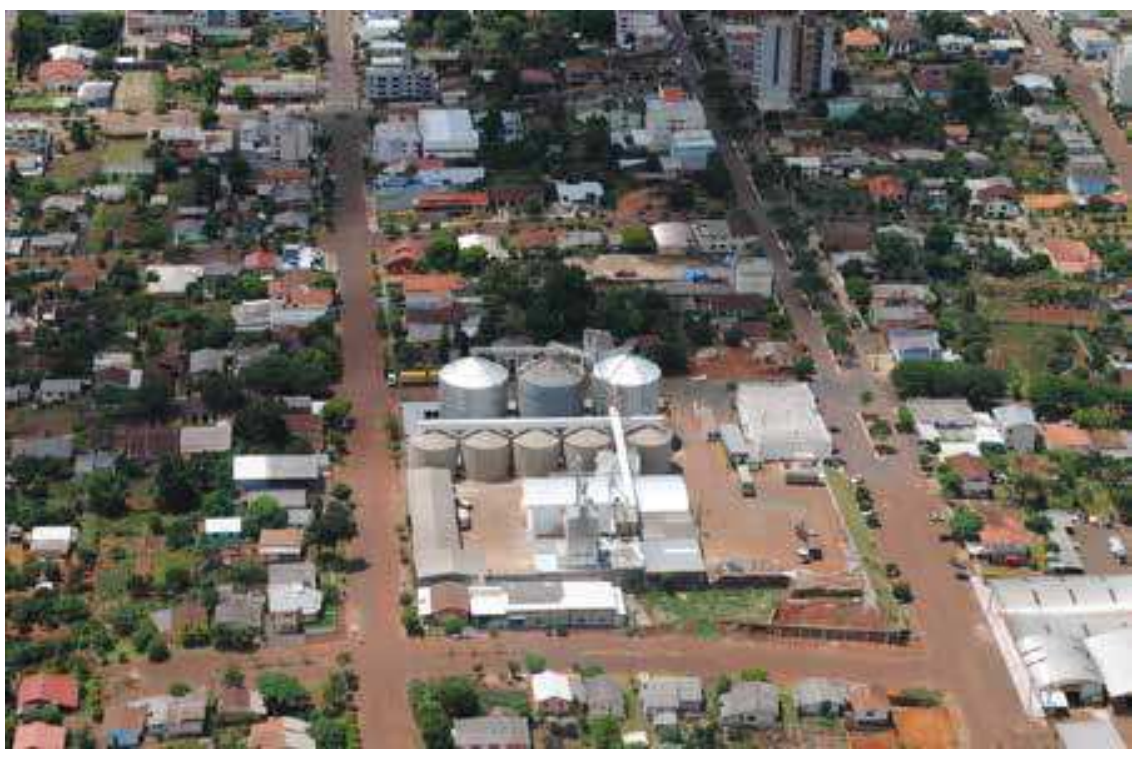

Figura 19 Agroindústria no bairro Nova Divineia. Fonte: Arquivo pessoal, 2016.

Através do mapa síntese de distribuição dos padrões (figura 21) é possível visualizar a concentração do Padrão Morfológico 01 nos bairros localizados ao leste da BR-282 e no bairro São José, também próximo à rodovia. 


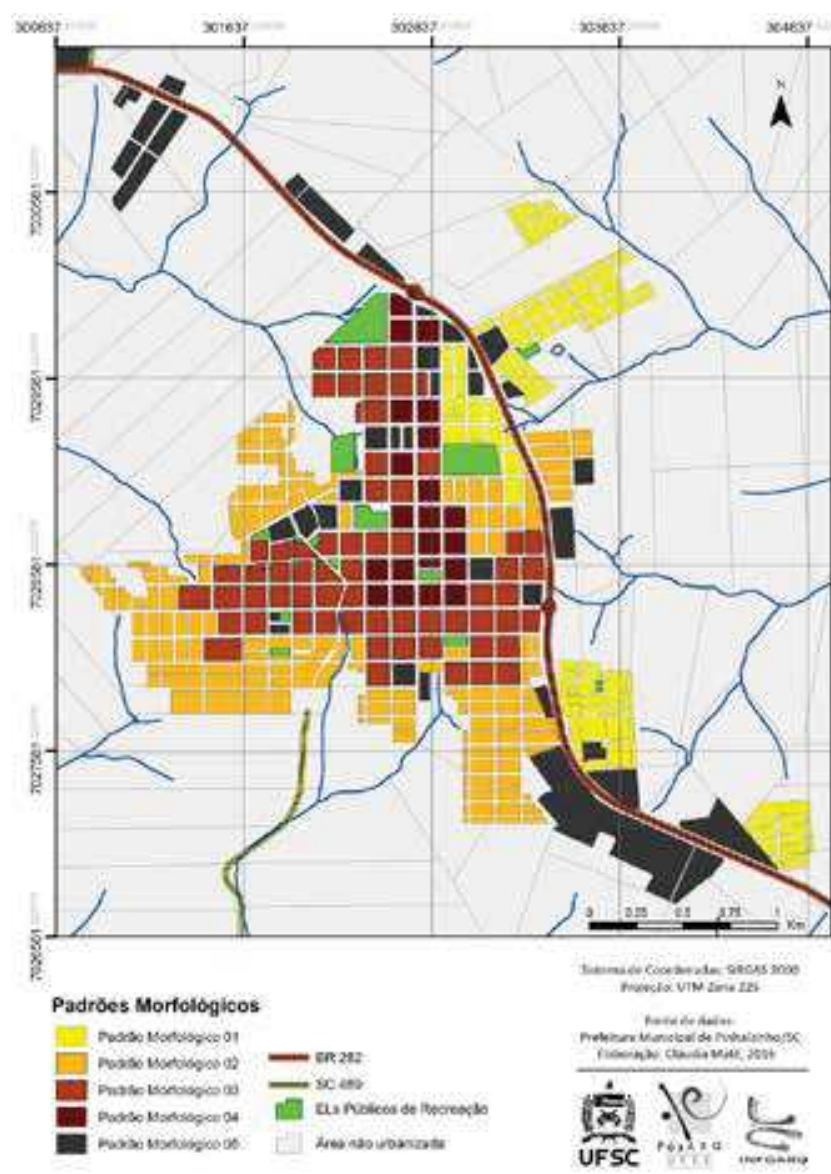

Figura 20 Mapa síntese dos padrões morfológicos.

Fonte: Elaborado por Cláudia Maté (2016) com base no mapa cadastral e dados vetoriais da Prefeitura Municipal de Pinhalzinho (2010).

Os Padrões 01 e 02 correspondem às áreas mais distantes da região central - e também as de ocupação mais recente. Através da comparação das formas de ocupação entre os dois primeiros padrões, pode-se constatar que os aspectos de maior influência sobre o espaço livre e construído são a localização e o rendimento médio. Fatores que também podem ser verificados nas diferenças na distribuição dos espaços públicos e na qualidade da infraestrutura urbana nos dois padrões.

Os Padrões 03 e 04 correspondem às áreas mais centrais, em sua maioria já consolidadas. Enquanto o Padrão 04 está concentrado no entorno da praça central e ao longo da avenida Brasília, o 03 está em sua área circundante. Neste predominam as edificações residenciais e os espaços livres permeáveis. Já no Padrão 04, os espaços livres vêm sofrendo transformações em função da verticalização, mudanças de usos e maior ocupação dos lotes. As quadras da área central e ao longo dos principais eixos viários são as que mais modificaram ao longo do processo de ocupação.

Pela leitura do mapa pode-se visualizar que as quadras referentes ao Padrão Morfológico 05 são pontuais em praticamente todos os bairros, porém concentram-se no Santo Antônio. Os grandes lotes industriais ao longo da BR-282, que a princípio não se configuram em quadras, foram inclusos no Padrão 05 por apresentarem semelhanças na forma de ocupação pelo espaço construído e na tipologia dos espaços livres privados. 
A partir da quantificação dos padrões morfológicos (tabela 1), percebemos a predominância dos Padrões 01 e 02, que, agrupados, correspondem a 296 das 432 quadras analisadas, representando $67 \%$ do total - seguidos pelo Padrão 03, presente em 63 quadras. Juntos, os três primeiros padrões somam 359 quadras, 82\% do total municipal. Esse número mostra que os espaços livres intraquadra verdes e permeáveis predominam no espaço urbano de Pinhalzinho, já que estão associados principalmente a esses três padrões.

Por outro lado, os padrões 04 e 05 correspondem a menos de $20 \%$ das quadras urbanas. Ambos estão associados com a maior ocupação do lote, com tendência à verticalização no Padrão 04 e à impermeabilização do solo no Padrão 05. A presença desses padrões em apenas 73 quadras, menos se considerados os lotes industriais separadamente, reiteram os dados anteriores acerca da verticalização restrita a poucas áreas e os espaços não permeáveis.

Tabela 1 Quantificação dos padrões no território urbano de Pinhalzinho

\begin{tabular}{l|c|c}
\hline Padrões Morfológicos & Número & \% do total \\
\hline Padrão 01 & 128 & $29 \%$ \\
\hline Padrão 02 & 168 & $38 \%$ \\
\hline Padrão 03 & 63 & $15 \%$ \\
\hline Padrão 04 & 21 & $5 \%$ \\
\hline Padrão 05 & 52 & $13 \%$ \\
\hline Total de Quadras & 432 & 100 \\
\hline
\end{tabular}

Fonte: Cláudia Maté (2016).

A respeito dos espaços livres privados encontrados nos cinco padrões, de forma geral, apresentam maiores dimensões e áreas mais permeáveis e vegetadas se comparados à realidade das grandes cidades brasileiras. $O$ sistema de espaços livres privados de Pinhalzinho compreende, entre os espaços mais conhecidos: jardins e quintais; espaços livres de caráter coletivo em edificações institucionais; lotes não edificados com presença de vegetação ou cultivos; pátios de estacionamento em áreas residenciais, comerciais e industriais; áreas de depósito nas indústrias e comércios de grande porte.

\section{CONSIDERAÇÕES FINAIS}

A análise dos espaços livres privados de Pinhalzinho, uma cidade pequena do oeste catarinense, com realidade urbana diferente da frequentemente estudada no âmbito nacional, resultou em dados ainda não encontrados em estudos dos grandes centros. Foram encontradas altas taxas de espaço livre intraquadra em todas as áreas da cidade: praticamente $60 \%$ das quadras analisadas apresentam mais de $70 \%$ de seu espaço livre de edificação. Enquanto nas grandes e médias cidades observa-se a predominância 
de tecidos urbanos com no máximo 30\% de espaços livres intraquadra, em Pinhalzinho as taxas de até $30 \%$ e de $30 \%$ a $50 \%$ de espaço livre intraquadra são inexpressivas.

No entanto, mesmo com os altos índices de espaços livres intraquadra, já é possível constatar que, como acontece em cidades maiores, os espaços livres privados vêm sendo reduzidos. Em Pinhalzinho, tais espaços vêm diminuindo em lotes verticalizados, em lotes residenciais horizontais de classes mais abastadas e em loteamentos populares - seja em função do aumento da ocupação do lote, da impermeabilização ou mesmo da diminuição do lote.

Na análise da verticalização por quadra foi possível identificar similaridades entre a predominância de quadras horizontais e a concentração das quadras mais verticalizadas nas áreas centrais e ao longo dos eixos viários. Porém, há grande diferença no número de edificações verticalizadas, uma vez que em Pinhalzinho a verticalização é restrita a poucas quadras e nenhuma delas apresenta mais de $50 \%$ de seus lotes verticalizados.

Em relação aos espaços livres privados, a quantidade de espaço livre intraquadra e a predominância de espaços livres verdes e permeáveis mostram-se bem diferentes da realidade de outras cidades analisadas pela Rede Quapá-SEL. O grande número de quintais e terrenos não edificados usados para cultivo, pomares e hortas é um dos resultados que merece destaque nesta pesquisa. Tais espaços produtivos, raramente encontrados em cidades maiores, são frequentes no espaço urbano de Pinhalzinho cidade de pequeno porte, com forte vínculo com o espaço rural.

\section{REFERÊNCIAS BIBLIOGRÁFICAS}

CAMPOS, A. C. M. A. Análise do Sistema de Espaços Livres da cidade brasileira: uma metodologia em elaboração. In: ENCONTRO NACIONAL DA ASSOCIAÇÃO NACIONAL DE PESQUISA E PÓS-GRADUAÇÃO EM ARQUITETURA E URBANISMO, 1, 2010, Rio de Janeiro. Anais... Rio de Janeiro: ANPARQ, UFRJ, UFF, 2010, p. $1-22$.

. et al. Análise do Sistema de Espaços Livres da cidade brasileira - uma metodologia em construção: estudo de caso para o município de São Paulo. Paisagem e Ambiente: ensaios. São Paulo: FAUUSP, v. 26, 2009 , p. $197-$ 210.

CUSTÓDIO, V. et al. Sistemas de espaços livres e forma urbana: algumas reflexões. In: ENCONTRO NACIONAL DA ASSOCIAÇÃO NACIONAL DE PÓS-GRADUAÇÃO E PESQUISA EM PLANEJAMENTO URBANO E REGIONAL (ENANPUR), 15, 2013, Recife. Anais... Recife: ANPUR, 2013, p. 1-16.

IBGE. Regiões de influência das cidades 2007. Ministério do Planejamento, Orçamento e Gestão. Instituto Brasileiro de Geografia e Estatística. Rio de Janeiro: IBGE, 2008. Disponível em: <https://ww2.ibge.gov.br/home/ geociencias/geografia/regic.shtm>. Acesso em: 20 out. 2014.

. Censo 2010. Disponível em: <censo2010.ibge.gov.br>. Acesso em: 20 out. 2014.

. Estimativas populacionais para os municípios brasileiros em 2014. Disponível em: <http://ibge.gov. br/home/estatistica/populacao/estimativa2014>. Acesso em: 15 mai. 2015.

MACEDO, S. S. Espaços Livres. Paisagem e Ambiente: ensaios. São Paulo: FAUUSP, n. 7, 1995, p. 15-56.

Quapá-SEL: um projeto de pesquisa em rede. São Paulo: FAUUSP, 2010.

. et al. Considerações preliminares sobre o sistema de espaços livres e a constituição da esfera pública no Brasil. In: TÂNGARI, V. R.; ANDRADE, R.; SCHLEE, M. B (Org.) Sistema de Espaços Livres: o cotidiano, apropriações e ausências. Rio de Janeiro: PROARQ, FAU, UFRJ, v. 1, 2009, p. 61-82. 
MAGNOLI, M. M. Espaços livres e urbanização: uma introdução a aspectos da paisagem metropolitana. 1982. 116 p. Tese (Livre Docência) - Faculdade de Arquitetura e Urbanismo da Universidade de São Paulo, São Paulo, 1982.

MATÉ, C. A cidade pequena através de seu sistema de espaços livres: o caso de Pinhalzinho/SC. 2016. 185 f. Dissertação (Mestrado em Arquitetura e Urbanismo) - Curso de Arquitetura e Urbanismo, Universidade Federal de Santa Catarina, Florianópolis, 2016.

MATTEI, L. Economia catarinense: crescimento com desigualdades regionais. In: ENCONTRO DE ECONOMIA CATARINENSE, 5, Florianópolis, 2011 . Anais... Criciúma: APEC, 2011.v. 1., p. 1-24.

PINHALZINHO. Cartografia do Plano Diretor Participativo do Município de Pinhalzinho. Prefeitura Municipal de Pinhalzinho, Santa Catarina, 2010.

Lei Complementar $n^{\circ}$ 144, de 28 de dezembro de 2012. Institui o Plano Diretor Participativo do Município de Pinhalzinho e dá outras providências. Prefeitura Municipal de Pinhalzinho, Pinhalzinho, SC, 2012. Disponível em: <https://leismunicipais.com.br/al/plano-diretor-pinhalzinho-sc>. Acesso em: 20 out. 2014.

QUEIROGA, E. F. Sistemas de espaços livres e esfera pública em metrópoles brasileiras. Resgate - Revista Interdisciplinar de Cultura, v. 19, 2011, p. 25-35.

Da relevância pública dos espaços livres: um estudo sobre metrópoles e capitais brasileiras. Revista do Instituto de Estudos Brasileiros, Brasil, n. 58, jun. 2014, p. 105-132.

. et al. Sistema de espaços livres privados - o outro lado do sistema de espaços livres urbanos: reflexões preliminares. In: Sistemas de Espaços Livres: conceitos, conflitos e paisagens. São Paulo: FAUUSP, 2011 , p. 33-53.

SOARES, B. R. Pequenas cidades: uma revisão do tema. In: OLIVEIRA, José Aldemir (Org.). Cidades brasileiras: territorialidades, sustentabilidade e demandas sociais. Manaus: UFAM, 2009, v. 1, p. 117-125.

SOUZA, F. B. Uma infraestrutura verde para áreas em urbanização junto a reservatórios: o caso de ltá (SC). 2009. Dissertação (Mestrado em Arquitetura e Urbanismo) - Faculdade de Arquitetura e Urbanismo da Universidade de São Paulo, São Paulo, 2009.

SPOSITO, E. S.; DA SILVA, P. F. J. Cidades pequenas: perspectivas teóricas e transformações socioespaciais. Jundiaí: Paco Editorial, 2013.

TÂNGARI, V. R.; ALMENTEIRO, D. G.; PARAHYBA, N. L. Open spaces and the urban form: morphological analysis in Rio de Janeiro. In: Portuguese Network of Urban Morphology, 2012, Lisboa. In: CONFERÊNCIA INTERNACIONAL PNUM 2012. Actas... ISCTE Instituto Universitário de Lisboa, 2012. p. 1.899-1.912.

Data de submissão: 30 nov. 2016

Data de aprovação: 1 jun. 2017 